\title{
Funcionarios de cuerpos de seguridad víctimas de homicidio. Estudio de casos del Área Metropolitana de Caracas*
}

\author{
KEYMER ÁvILA**
}

Artículo recibido: 6 de septiembre de 2015

Artículo aprobado: 15 de marzo de 2016

Doi: http://dx.doi.org/10.12804/desafios28.2.2016.01

Para citar este artículo: Ávila, K. (2016). Funcionarios de cuerpos de seguridad víctimas de homicidio. Estudios de casos del Área Metropolitana de Caracas. Desafíos, 28(2): 17-64. Doi: http://dx.doi.org/10.12804/desafios28.2.2016.01

\section{Resumen}

En este trabajo se estudian los casos de homicidios intencionales ocurridos durante 2013 en el Área Metropolitana de Caracas, en donde las víctimas fatales fueron funcionarios de los cuerpos de seguridad del Estado. El objetivo es caracterizar el

\footnotetext{
* Este artículo está inserto dentro de la investigación colectiva: "Estudio sobre el impacto de la proliferación de armas de fuego, las economías ilícitas y la militarización de la seguridad ciudadana en la ocurrencia de homicidios en Venezuela" de la Red de Activismo e Investigación por la Convivencia (REACIN); así como en el seminario "Homicidios dolosos en Venezuela", que se adscribe a las líneas de investigación "Violencia y problemas sociales" y "Sistemas Penales" del Instituto de Ciencias Penales (ICP) de la Universidad Central de Venezuela (UCV).

** Abogado Magna cum Laude, egresado de la Universidad Central de Venezuela (UCV). Máster Oficial en Criminología y Sociología Jurídico Penal, Universitat de Barcelona. Investigador del ICP de la UCV. Profesor de Criminología en pre y postgrado de la misma universidad. Colaborador de la Red de Apoyo por la Justicia y la Paz y del Observatorio del Sistema Penal y los Derechos Humanos de la UB. Miembro de la Asociación Latinoamericana de Derecho Penal y Criminología (ALPEC). Correo electrónico: keymerguaicaipuro@, gmail.com
} 
fenómeno y dar respuesta a las preguntas más básicas sobre el mismo. Para ello se analizan las principales discusiones sobre la violencia contra la policia, tanto las que se han dado en ámbitos académicos como en los espacios mediáticos coyunturales. Posteriormente, se contrastan los debates anteriores con los resultados de la investigación empirica realizada. Se desmitifican algunos supuestos sobre estos casos.

Palabras clave: homicidios, vulnerabilidad policial, victimización policial, violencia policial, cuerpos de seguridad.

\title{
Law-Enforcement Officers Killed. Case Studies from the Metropolitan Area of Caracas
}

\begin{abstract}
In this article I discuss intentional homicide cases in the metropolitan area of $\mathrm{Ca}$ racas, Venezuela, during 2013 in which police officers were the victims. The article describes the trends of such homicide cases and discusses personal and situational variables surrounding the events. I begin with a preliminary discussion of both the academic literature and media reports on this issue, contrasting the debate and the suggestions made in both sources with data from empirical studies. As a result, some assumptions about those cases are demystified.
\end{abstract}

Keywords: Homicide, police risk, police victims, police violence, security forces.

\section{Funcionários das forças de segurança vítimas de homicídio. Estudo de casos da Área Metropolitana de Caracas}

\begin{abstract}
Resumo
Neste trabalho estudam-se os casos de homicídios intencionais ocorridos durante 2013 na Área Metropolitana de Caracas, onde as vitimas fatais foram funcionários das forças de segurança do Estado. O objetivo és caracterizar o fenômeno e dar resposta às perguntas mais básicas sobre o mesmo. Para isso, analisam-se as principais discussões sobre a violência contra a policia, tanto as que se tem dado em âmbitos acadêmicos quanto nos espaços mediáticos conjunturais. Posteriormente, contrastam-se os debates anteriores com os resultados da investigação empirica realizada. Se desmitificam alguns supostos sobre estes casos.
\end{abstract}


Palavras-chave: Homicídios, vulnerabilidade policial, vitimização policial, violência policial, forças de segurança.

\section{Introducción}

Durante los últimos años, los medios de comunicación han posicionado al homicidio de policías en la agenda pública. Según información periodística, en 2012 hubo entre 104 y 350 casos; en 2013, entre 99 (Chirinos, 2013; Ramírez, 2013) y 295, y en 2014 las informaciones varían entre 230 y 338 (Izquiel, 2015; El Universal, 2015). Algunos han llegado incluso a afirmar que entre enero de 2011 y mayo de 2015 han ocurrido unos 1.205 homicidios de funcionarios de cuerpos de seguridad en el país (FUNDEPRO, 2015). Ninguna de estas cifras son confiables, por las razones siguientes: 1) su criterio "mediático", ya que casi nunca se explica la metodología empleada y en muchas ocasiones carecen de un mínimo de rigurosidad; además, en el caso de este tipo de homicidios la cifra que presentan está usualmente por debajo de las cifras reales a las que se acerca más la información oficial; 2) se desconoce la fuente de la información, lo que genera dudas sobre su certeza; 3) por la polarización política en la que se encuentra inmersa el país, de la cual no escapan los medios de comunicación (ni públicos, ni privados), en ocasiones se presentan estos fenómenos de manera interesada y distorsionada (Ávila, 2010); 4) el silencio oficial sobre el fenómeno se constituye como un problema en sí mismo que genera todos los problemas anteriores. Estas variables dificultan cualquier análisis sobre las tendencias de los homicidios de los funcionarios policiales en el país.

Por otra parte, aunque se ha dado un posicionamiento mediático reciente de este fenómeno, es necesario destacar que no es nuevo. En la obra pionera de Del Olmo (1990) titulada Violencia policial en las calles de Caracas se habían contabilizado solo en esta ciudad la muerte violenta de 148 funcionarios entre los años 1982 y 1986.

El caso del Área Metropolitana de Caracas (AMC) merece especial atención. Está conformada por el municipio Libertador del Distrito 
Capital ${ }^{1}$ y los municipios Sucre, Baruta, Chacao y el Hatillo del estado Miranda. ${ }^{2}$ Además, es considerada la segunda zona más poblada del país; para el año 2013 tenía una población aproximada de 3257079 habitantes (INE). Tradicionalmente, el AMC es la que tiene las tasas más altas de homicidios del país (Sanjuán, 1997; 2008; 2012). ${ }^{3}$ Según los datos del Cuerpo de Investigaciones Científicas, Penales y Criminalísticas (CICPC) en esta área geográfica también ocurre la mayor cantidad de casos de homicidios en los que las víctimas son funcionarios pertenecientes a los cuerpos de seguridad.

En 2013 el AMC aportó la mayor cantidad de casos (18,3\%) y de funcionarios fallecidos en el país (19,43\%); es por ello que constituye el espacio geográfico de referencia para el presente análisis.

Este trabajo plantea la necesidad de conocer detalladamente las características del fenómeno en el AMC, para tener la capacidad de responder preguntas básicas: ¿Qué está ocurriendo? ¿Dónde? ¿Cuándo? ¿Quiénes son los involucrados? ¿Cómo? ¿Por qué? Las instituciones del Estado deben tener un conocimiento claro y preciso sobre el fenómeno, saber con qué información relevante y de calidad cuenta para el análisis y diseño de una política pública de reducción de los homicidios en general y de los funcionarios de los cuerpos de seguridad en particular (Del Olmo, 1990; Matthews, 2014; Monsalve y Gabaldón, 2012). Con base en esta información pueden establecerse hipótesis y contextos explicativos del fenómeno concreto. No se puede controlar ni abordar un fenómeno sin el conocimiento de las variables más básicas.

El objetivo de la investigación fue caracterizar los casos de homicidios dolosos en los que las víctimas fueron funcionarios pertenecientes a

\footnotetext{
1 Único municipio del mencionado Distrito, asiento de los órganos del Poder Nacional, es la cuarta entidad más poblada de Venezuela después de los estados Zulia, Miranda y Carabobo (Instituto Nacional de Estadísticas -INE-).

2 Artículos 18 de la Constitución de la República Bolivariana de Venezuela (CRBV) y 2 de la Ley Especial del Régimen Municipal a dos niveles del AMC.

3 Para 2011 llegó a tener una tasa de homicidios 90,84, mientras que la del país era de 47,84 (CICPC en Fernández y Tabares, 2013).
} 
cuerpos de seguridad del Estado, específicamente los ocurridos en el AMC durante el año 2013. Por cuerpos de seguridad del Estado se entenderán los cuerpos policiales en sus tres niveles político-territoriales (municipal, estadal y nacional), así como funcionarios militares, ya que ese ha sido el criterio seguido por el Cuerpo de Investigaciones Científicas, Penales y Criminalísticas (CICPC) cuyos expedientes son el objeto del análisis.

La investigación fue de carácter exploratorio y descriptivo. Para la misma se realizó trabajo de campo y se diseñó un instrumento para la recolección de información de los expedientes del CICPC sobre casos de homicidios en los que los funcionarios de los cuerpos de seguridad fueron víctimas. El instrumento fue aplicado dentro de las propias sedes de la institución. Se hizo un censo conformado por la totalidad de los casos conocidos por el CICPC durante el año 2013, ocurridos en la AMC. El total de casos fue de 56.

Para lograr el acceso a la información, a comienzos de 2014, se planteó ante el Ministerio de Interior y Justicia (MIJ), a través del Consejo General de Policía (CGP), un proyecto de investigación de homicidios dolosos en el país, cuya primera fase se concentraría en los casos de la AMC. El Ministro comprendió la importancia del mismo y autorizó el inicio de las actividades a finales de marzo. Meses después se dio un cambio de Ministro, justo cuando se culminaba el trabajo de campo (lo que volvió a ocurrir, por segunda vez, cinco meses más tarde) y con ello también las autoridades del CGP. Lamentablemente, el nuevo Secretario Ejecutivo del CGP no consideró necesaria la continuidad del proyecto. Ante esta situación, se entregaron formalmente al CGP los instrumentos con toda la información recabada, y a partir de ese momento se llevó a cabo, por cuenta propia, el procesamiento y análisis de los resultados, los cuales se presentan parcialmente en este trabajo. Es de advertir que estos se hicieron llegar también a las autoridades correspondientes (MIJ, CICPC y Ministerio Público) en procura de coadyuvar en el diseño de políticas públicas en estas materias. 


\section{Discusiones sobre la violencia contra la Policía}

\subsection{El debate en la bibliografía especializada}

En Latinoamérica no se conocen trabajos académicos cuyo objetivo principal sea la vulnerabilidad de funcionarios policiales, mucho menos estudios de casos en los que estos resultan víctimas de homicidios. Por el contrario, lo que sí existe es abundante literatura sobre policías como victimarios, trabajos que giran en torno al tema de los derechos humanos, el uso de la fuerza y la violencia policial (Del Olmo, 1990; Fondevila \& Meneses, 2014; Gabaldón \& Birkbeck, 2003; Zaffaroni, 1993). Gabaldón (2013) señala incluso que en los diagnósticos de la Comisión Nacional para la Reforma Policial (CONAREPOL) de 2006 este tema no fue considerado.

Solo en el mencionado trabajo de Del Olmo (1990) se hace alusión a este fenómeno, por lo que constituye una referencia fundamental para el presente análisis; sin embargo, el objetivo de este era mucho más amplio.

En contraste, en el contexto estadounidense los ataques sufridos por la policía y la vulnerabilidad de los funcionarios ante los mismos son temas de interés para la investigación criminológica (Gabaldón, 2013). ${ }^{4}$ La investigación norteamericana sobre estos temas tiene un enfoque predominantemente organizacional y funcional; un punto en común es hacer estudios con líneas de tiempo bastante amplias. $\mathrm{Al}$ analizar las cifras sobre asesinatos de policías entre 1930 y 1998 la tendencia de las últimas décadas es hacia la baja (Fidell \& Pate, 1997; Kaminski \& Marvell, 2002; Batton \& Wilson, 2006). Sus explicaciones sobre los homicidios de los funcionarios policiales giran, básicamente, en torno a las ideas siguientes: 1) el servicio de policía es un oficio de alto riesgo, por lo que habría que concentrarse en controlar y reducir las exposiciones de los funcionarios, minimizando así su vulnerabi-

\footnotetext{
4 Agradezco al profesor Gabaldón la recomendación y acceso a la literatura norteamericana sobre esta materia, así como sus observaciones, críticas y consejos para la elaboración de este artículo.
} 
lidad (Kraus, 1987; Fridell \& Pate, 1997; Kaminski \& Martin, 2000; Kaminski et al., 2003; Batton \& Wilson, 2006); 2) mejoras tecnológicas, como la introducción del chaleco antibalas en la década de los setenta y el incremento de la calidad de la formación y entrenamiento de los funcionarios en tácticas policiales (que van desde destrezas verbales, mediación, técnicas físicas para el control de sujetos, hasta el uso de armas de fuego), habilidades defensivas ante ataques corporales (golpes, patadas, y retención del arma) y encuentros con delincuentes armados; estos han contribuido a la disminución de la victimización policial (Fridell \& Pate, 1997; Kaminski \& Martin, 2000; Kaminski \& Marvell, 2002; Batton \& Wilson, 2006); 3) también se han realizado intentos para explicar este fenómeno a través de teorías criminológicas, tales como la teoría de las oportunidades y las actividades rutinarias, las teorías del control, la desorganización social y las de la tensión (Kaminski et. al, 2003; Batton \& Wilson, 2006); 4) sin embargo, hay cierto consenso en que los resultados de sus investigaciones no son generalizables, concluyentes, ni definitivos; incluso en ocasiones pueden ser contradictorios: tienen "poca coherencia global en los resultados y son estadísticamente insignificantes" (Batton \& Wilson, 2006; Kaminski et al., 2003; Kaminski \& Martin, 2000; Kaminski \& Marvell, 2002).

Con estos resultados puede plantearse que la violencia contra la policía y la violencia general comparten causas estructurales comunes y, por lo tanto, los factores que se asocian con la violencia general también pueden ser de utilidad para el abordaje de la violencia contra la policía. Razón por la cual, entre las teorías tomadas como marcos explicativos, las de tipo más macrosocial, -como las teorías de la tensión (Merton, 1938) y la desorganización social (Shaw \& Mckay; 1969)- pueden ser las más consistentes (Batton \& Wilson, 2006; Kaminski et al., 2003). Esto abre toda una gama de posibilidades de investigación de este fenómeno desde perspectivas críticas, tales como el socioconstruccionismo, las teorías del conflicto, el realismo crítico, etc., las cuales serán tomadas en cuenta transversalmente para el presente análisis.

Hay dos aspectos importantes de los resultados de las investigaciones norteamericanas que son de especial interés para este trabajo: 1) estos estudios se concentran en los oficiales que han sido víctimas 
de homicidio en actos de servicio (Batton \& Wilson, 2006; Kraus, 1987). Kaminski y Martin (2000) al analizar la satisfacción de los oficiales con su formación en tácticas de control y de defensa comprobaron que $69 \%$ de los mismos han sido víctimas de ataques violentos en el ejercicio de sus funciones; 2) el riesgo de muerte violenta no se limita a oficiales inexpertos o descuidados; de los oficiales asesinados en 2002, $42 \%$ tenía más de 10 años en la institución, y alrededor de $66 \%$ llevaban chalecos antibalas (FBI, 2004, citada en Batton \& Wilson, 2006).

Así, los riesgos que implica la prestación del servicio de policía y la experiencia de los oficiales para hacer frente a los mismos constituyen dos supuestos fundamentales para estos estudios. Ambos fueron contrastados con los resultados de la presente investigación, y a su vez se vincularon de alguna manera con el discurso mediático sobre estos fenómenos, que serán descritos a continuación.

\subsection{El debate mediático}

\subsubsection{Los "opinólogos"}

En el trabajo La instrumentalización del delito:politica, empresas de comunicación e inseguridad (Ávila, 2010) se explica cómo las empresas de comunicación (públicas y privadas) modelan la agenda pública e impactan directamente en la política criminal del país. Esta agenda puede o no reflejar la magnitud real del fenómeno; lo importante son los intereses de quienes tienen el poder de definir la mencionada agenda. En este contexto surgen unos actores que contribuyen a la formación de la agenda securitaria y a la definición de sus temas; estos sujetos se denominarán "opinólogos". Estos son personajes que, sin tener la formación académica ni técnica especializada, y sin investigaciones serias validadas por especialistas reales, emiten opiniones basadas en el sentido común, en preconcepciones y prejuicios sobre los problemas securitarios en los medios de comunicación. Se autodenominan "expertos" en algunos temas porque les dan declaraciones a algunos periodistas con los que tienen relaciones de amistad o empatía de alguna naturaleza. Estas ideas distorsionadas y desinformadas impiden tener una clara comprensión del fenómeno securitario y terminan 
influenciando de alguna manera las decisiones político criminales, agudizando así los problemas. Además, presentan cifras sin explicar la metodología empleada, ni su fuente y hacen "cálculos" y "estimaciones" que no describen el fenómeno real.

Estos “opinólogos” serían una categoría especial de los “empresarios morales" descritos por Becker (1971) y Birkbeck (2001). Este último autor, cuando intenta caracterizar a los "empresarios morales" venezolanos de la segunda mitad del siglo XX, obtiene los siguientes resultados:

1. Los políticos conforman el grupo más grande (42,5\%), seguido de los columnistas y otros periodistas, quienes representan casi un tercio del total. Los profesionales especializados sobre estas materias apenas representaron un 18,2\%.

2. Hay una "ausencia, casi por completo, del discurso estrictamente técnico en el abordaje periodístico del tema" (2001, p. 382). La gran mayoría de los artículos $(89,5 \%)$ no representaba el discurso técnico; era más bien de tipo "moral" o "melodramático". 5

3. Concluye que los principales beneficiarios de estos discursos melodramáticos son quienes los emiten.

Una vez realizada esta introducción necesaria, se expondrá a continuación cuál ha sido el relato construido por los medios sobre el fenómeno de los homicidios de funcionarios de los cuerpos de seguridad.

\subsubsection{Los mitos construidos por el discurso mediático} sobre las muertes de los funcionarios de los cuerpos de seguridad

A partir del año 2012 comienzan a visibilizarse con más frecuencia en los medios de comunicación, especialmente en los impresos, casos de funcionarios de los cuerpos de seguridad víctimas de homicidios. Las

5 “[...] forma de dramatización que, haciendo uso frecuente de metáforas, contrapone el bien y el mal en términos tan sencillos que la diferencia entre uno y otro resulta tosca" (Birkbeck, 2001, p. 388). 
matrices que se posicionan a partir de este momento van forjando en la "opinión pública" los siguientes mitos:"

\section{Primer mito: El asesinato de funcionarios de cuerpos de segu- ridad es un fenómeno de los últimos tiempos. En el primer cua-} trimestre de 2015 se le dio un especial énfasis. ${ }^{8}$ Sin embargo, desde años anteriores se venía informando sobre estos casos. Como se ha señalado, Del Olmo en la década de los 80 había analizado este fenómeno que, ya para esa época no era excepcional ni novedoso. La discusión, entonces, podría girar en torno al aumento del número de casos en los últimos tiempos, tal como lo señalan las empresas de comunicación. No obstante, como se afirmó en la introducción, la ausencia de cifras confiables durante una línea de tiempo significativa dificulta verificar esta hipótesis. Lo que sí es falso es que estos casos sean una novedad de los últimos años en Venezuela.

\section{Segundo mito: Los matan por su condición de policías, lo que sugiere un vínculo con el ejercicio de sus funciones. Al contrario} de lo que sucede con las personas que mueren a manos de la policía, a las que se les califica como "delincuentes" para legitimar sus muertes y dar por sobreentendido que el contexto de estos eventos es un "enfrentamiento" (Del Olmo, 1990), el discurso a través del cual se informa de los casos de oficiales fallecidos los victimiza, los

\footnotetext{
6 Entendida como "opiniones sobre temas controvertidos que pueden expresarse en público sin aislarse” (Noelle-Neuman, 1995, p. 88).

7 Entendidos como: "Persona o cosa a las que se atribuyen cualidades o excelencias que no tienen, o bien una realidad de la que carecen" (DRAE, [en línea]). La cualidad de mito entonces no es absoluta, sería provisional, es decir, hasta que se demuestre lo contrario.

8 El detonante se dio en abril, a partir del asesinato de la oficial Osmary Tavare, que fue grabado y difundido por las redes sociales (El Parroquiano, 2015). A partir de ese evento, el tema se posicionó en la agenda. La respuesta oficial a esta matriz será señalada en el "tercer mito". Incluso hubo una marcha de policías en contra de este fenómeno ese mismo mes (Rísquez, 2015). Además, entre enero y agosto de 2015, según conteo periodístico, han matado a unos 8 escoltas, 3 de diputados y 1 de un famoso director de orquesta, lo que motiva que sean hechos noticiosos (Últimas Noticias, 2015; Globovisión, 2015; El Nacional, 2015). Este discurso es instrumentalizado por sectores de oposición como una muestra del fracaso de las políticas securitarias del Gobierno, transmitiendo un mensaje cuya idea principal es que "ni siquiera los policías están seguros en Venezuela".
} 
presenta como vulnerables ante la delincuencia desatada, dejando implícito que murieron por ejercer su función. ${ }^{9}$ Este es un claro ejemplo de cómo la retórica sobre el delito y la lucha en su contra tiene una lógica moralista, funcionalista, consistente en degradar a los sujetos etiquetados como delincuentes y enaltecer a quienes los combaten (Baratta, 1998; Del Olmo, 1990; Durkheim, 1893, 1895; Garfinkel, 1956). En resumen: las personas que mueren por acción de las policías son "delincuentes", "malas personas" que de alguna manera merecían ese destino; en contraste, los policías que resultan muertos lo hacen porque están expuestos a mayores riesgos, debido a sus funciones, son "víctimas" y por lo tanto "buenas personas". En el presente estudio se verificará si efectivamente los oficiales víctimas de homicidio se encontraban o no en ejercicio de sus funciones.

\section{Tercer mito: Los victimarios de los funcionarios fallecidos son paramilitares colombianos. Hay un discurso oficial según el cual el} paramilitarismo colombiano es un factor importante de desestabilización política y un generador de inseguridad ciudadana en Venezuela; esta retórica es un fenómeno de los últimos años (Antillano, 2012), que parece tener un empuje a raíz del asesinato del diputado Robert Serra en el año 2014, en el que presuntamente participaron ciudadanos colombianos. ${ }^{10}$ A partir de ese evento, se puede apreciar en el discurso oficial una acusación recurrente contra algunos sectores de la oposición presuntamente vinculados con paramilitares colombia-

\footnotetext{
$9 \quad$ "Los jubilados convocaron junto a organizaciones no gubernamentales del área, a una serie de actividades para rendir homenaje a la memoria de los funcionarios caídos" (FUNDEPRO, 2015); "Pedro Rangel, indicó que, según los estudios que su equipo ha llevado a cabo, los policías han sido víctimas del hampa y de la venganza vinculada al trabajo policial, "nada que ver con la vinculación de policías con hechos delictivos" (Iglesias, 2010, [en línea]); "Da lástima lo que está sucediendo en el país. Cómo es posible que a un funcionario que lo sale a cuidar a uno le pase esto" (Rísquez, 2015, [en línea]); "Las estadísticas arrojan que la segunda causa de muerte de los efectivos se debe a procedimientos policiales" (El Universal, 2015, [en línea]).

10 Sobre este particular ver: Telesur (2014). Paramilitar colombiano dirigió asesinato de diputado venezolano [Archivo de video]. Recuperado de http://www.telesurtv.net/news/ Paramilitar-colombiano-dirigio-asesinato-de-diputado-venezolano-20141015-0076.html; Globovisión (2015). Claves ¿Quién es Julio “Julito” Vélez [Archivo de video]. Recuperado de http://globovision.com/claves-quien-es-julio-julito-velez/
} 
nos, quienes estarían implicados en acciones desestabilizadoras en el país, entre las que se encontrarían asesinatos selectivos de dirigentes cercanos al gobierno y de funcionarios policiales. Algunos ejemplos sobre cómo el Ministro de Interior establece relaciones causales entre grupos paramilitares y el asesinato con fines políticos de funcionarios de los cuerpos de seguridad son los siguientes: "Tenemos pruebas de que los recientes actos en los que han perdido la vida nuestros funcionarios policiales son parte de un plan perverso" "No es casualidad: Persiste el paramilitarismo en los municipios Sucre, Baruta y Chacao los más violentos del país del desgobernado Edo. Miranda [municipios y Estado gobernados por la oposición]" "La Mafia Amarilla mientras juega a hacer política, mantiene pactos con la delincuencia criminal y con los paracos que le envía Álvaro Uribe" "El fondo político que busca es selectivo, progresivo y escalonado [...] Me atrevo a decir que tengo pruebas y a buen resguardo de porque es perverso su uso político" "A los comandantes de las policías se les ha dado la orientación de extremar todas las medidas de seguridad, pero es perverso para tratar de tomar liderazgo es perverso" (González, 2015, [en línea]). El presente estudio verificará si efectivamente el perfil de los victimarios se adecúa a la hipótesis oficial descrita.

Cuarto mito: Los funcionarios de seguridad deben andar armados también fuera de servicio, porque el arma les brinda más seguridad. "Los policías lo son las 24 horas del día. Ellos no se deslastran de sus funciones ni de su entrenamiento cuando están libres" (Iglesias, 2010, [en línea]). Esta idea está muy arraigada en la cultura policial y militar, y resulta un tema indiscutible en esos espacios. El presente estudio verificará si efectivamente el andar armados fuera de las horas de servicio fue positivo para los funcionarios víctimas de homicidio.

Quinto mito: Los delincuentes están mejor armados que los policías. Según FUNDEPRO los funcionarios de seguridad "prácticamente trabajan con las uñas, no tienen patrullas, equipos de radio y les limitan las armas de fuego" (2015, [en línea]). En el mismo sentido, la Federación Nacional de Policías Jubilados y Pensionados de Venezuela ha señalado que los funcionarios policiales perdieron 
las ventajas que tenían ante el hampa desde el punto de vista armamentístico, logístico y financiero "desventaja que se ha evidenciado en el asesinato de varios funcionarios policiales, quienes cayeron abatidos tras quedar sin municiones con las que repeler el ataque que sufrían" (2015, [en línea].). "Los policías no comercializamos ni tenemos acceso a un fusil AK 47 y es con ese tipo de armas que nos atacan los delincuentes" (Rísquez, 2015 [en línea]). El presente estudio caracterizará las armas de víctimas y victimarios para ver en realidad que tanto difieren entre sí.

Sexto mito: Los matan porque viven en los mismos barrios que sus victimarios (los delincuentes). "De acuerdo con Pedro Rangel, los policías no pueden vivir en las mismas zonas donde viven, conviven y “trabajan” los malandros. 'Allí, los uniformados son presa fácil del hampa, pues todos conocen sus rutinas', concluyó el experto” (Iglesias, 2010, [en línea]). Si bien la idea de estar en "proximidad espacial con los delincuentes motivados tiende a aumentar la frecuencia de los contactos regulares de estos con sus posibles víctimas" (Cohen et al., 1981, p. 507), ésta ha sido planteada para la delincuencia común y no se ha comprobado aún a casos de homicidios contra funcionarios policiales (Kaminski et al., 2003). El presente estudio describirá las relaciones existentes entre el lugar del hecho y el lugar de residencia de víctimas y victimarios, y qué tanto coinciden estos últimos.

\section{Otras retóricas que sirven como contextos explicativos generales}

\subsection{La inseguridad y sus cifras}

La inseguridad en Venezuela se ha posicionado durante los últimos años en los primeros lugares de la agenda mediática y, en consecuencia, en la agenda política del país (Datanalisis, 2014; IVAD, 2015). Como se mencionó en la introducción, el acceso a la información se ha restringido durante la última década, como consecuencia de diversas coyunturas político electorales y de polarización que se han dado en Venezuela durante los últimos tres lustros; esto ha generado en algunos sectores de la oposición política la aplicación de fórmulas 
diversas para "calcular" las cifras de delitos, presentando números procedentes de metodologías más cercanas a la futurología y a la adivinación que a la descripción objetiva del fenómeno en sí. El silencio oficial y las especulaciones de la oposición no contribuyen en absoluto a un adecuado análisis, ni a la toma de decisiones acertadas sobre el problema; por el contrario, crean un clima que distorsiona estos procesos. Esto ha sucedido incluso con las cifras de homicidios.

El homicidio es considerado como la conducta delictiva más grave y es un indicador indiscutible de la situación objetiva de la inseguridad y de la violencia delictiva. Venezuela tiene una de las mayores tasas de homicidio del mundo; para 2015, la Fiscal General informó que la tasa llegó a 58 homicidios por cada cien mil habitantes (Ministerio Público, 2016, p. 45). Estas cifras resultan alarmantes cuando se contrastan con la tasa mundial de homicidios que para el año 2012 había sido estimada en 6,2 (ONUDD, 2013); en este mismo sentido, la OMS estima que una tasa de 10 puede considerarse ya como una epidemia. Es importante tener en cuenta que la tendencia de los homicidios en América Latina y el Caribe durante la última década también ha sido creciente (PNUD, 2013; BBC Mundo, 2014). En el caso venezolano, la tendencia en el aumento de los homicidios ha sido progresiva durante los últimos sesenta años (Briceño et al., 1997; Briceño, 2009, 2012; Sanjuán, 1997, 2003, 2013).

\subsection{La hipertrofia policial}

La tasa de encuadramiento es un estándar construido internacionalmente para estimar el número de funcionarios policiales de acuerdo a la densidad poblacional; en años recientes se ha establecido como medida entre 300 y 400 funcionarios por cada cien mil habitantes (pcmh). Sin embargo, este estándar se basa en estadísticas internacionales, por lo que no hay que perder de vista que en cada país se pueden estar utilizando criterios disímiles para estimar el número de agentes. Por ello se recomienda su complemento con otros indicadores, aunque sigue siendo válido como medio para comparar y describir el pie de fuerza policial de un país (Antillano \& CPDHUCV, 2007). 
La hipertrofia policial es el crecimiento acelerado y desmedido de la institución policial. Todo proceso de masificación en la prestación de un servicio debe tener un ritmo racional, que debe ser evaluado técnica y permanentemente para asegurar la calidad y evitar que el pretendido remedio termine siendo peor que la enfermedad. Desde el año 2006, a partir del proceso llevado a cabo por la CONAREPOL, el número de todas las policías preventivas (en los 3 niveles político territoriales) se ha incrementado considerablemente; ya desde el año 2007 el país se encontraba por encima de los estándares internacionales de tasa de encuadramiento policial (429 policías PCMH) (Antillano \& CPDHUCV, 2007; Antillano, 2014).

Así, se pasó de un total de 114.463 funcionarios policiales en 2006 (Sanjuan, 2012) a más de 140.000 para mediados de 2015 (Bernal, 2015). Esto significa que el pie de fuerza policial ha tenido un crecimiento aproximado de $22,3 \%$ en los últimos nueve años, incrementándose la tasa de encuadramiento policial 28 puntos más, para llegar a 457 policías pcmh, 107 puntos por encima del estándar internacional. El caso de la PNB es emblemático; según información oficial, con apenas seis años de creación ha alcanzado un número aproximado de 14.739 funcionarios (PNB, 2015).

Con base en la evidencia anterior podría afirmarse que en Venezuela no hacen falta más policías, sino mejores policías, mejor organización, mayor supervisión y control sobre los funcionarios, y una mejor y equitativa distribución de los mismos sobre el territorio.

\subsection{Las armas}

Según el CICPC un 90,5\% de los casos de homicidios son consecuencia del uso de armas de fuego (Fernández \& Tabares, 2013). Así entonces, la disponibilidad de armas en los casos de homicidio es una variable muy importante, y en los casos en los que los funcionarios de los cuerpos de seguridad son víctimas lo son más aún, tal como quedará demostrado más adelante. Investigadores como Bandeira y Bourgois (2006) y Banderia (2011) afirman que una de las principales fuentes del mercado ilegal de armas son las armas de los particulares 
y las de los cuerpos de seguridad del Estado. En la presente investigación se observarán resultados de interés sobre este particular.

\subsection{Violencia policial}

Si el acceso a las cifras delictivas, en general, y de homicidios comunes, en particular, es difícil y en los casos en los que estas son disponibles la calidad del dato no es confiable, la situación es mucho más crítica en los casos de violencia policial, especialmente en relación con los homicidios cometidos por funcionarios de los cuerpos de seguridad (Del Olmo, 1990; Gabaldón, 1993; Antillano, 2010; Fondevila \& Meneses, 2014).

Uno de los procesos de sistematización más continuos que se encuentran disponibles sobre violaciones al derecho a la vida cometidos por cuerpos policiales y militares es el de la ONG PROVEA. Si bien es un trabajo meritorio llevar año tras año el conteo de estos casos, la fuente de información son las denuncias que reciben directamente así como las noticias de las empresas de comunicación, las cuales vienen matizadas por intereses diversos (Ávila, 2010; Antillano, 2014), lo que no garantiza su fiabilidad. Por otra parte, la cantidad de casos que no llegan a ser conocidos por las ONG es grande; así, por ejemplo, mientras que PROVEA entre el año 2000 y 2007 contabilizó 1.447 casos, el Ministerio Público en ese mismo período contabilizó 6.140 (Ávila, 2013). Lamentablemente, las fuentes oficiales tradicionales para estos temas desde esa fecha no han informado más sobre este fenómeno. Una alternativa interesante ante esta situación la ofrecen Fondevila y Meneses (2014): estudiar las “muertes por intervención legal” presentes en los anuarios de mortalidad de los ministerios de salud.

$\mathrm{Al}$ analizar estas diversas fuentes puede apreciarse que, según PROVEA, la tendencia de estos casos es al aumento. Sin embargo, si se contrasta con la información oficial la tendencia es a la baja. También se observa una enorme diferencia entre los datos de la ONG y los del Ministerio del Poder Popular para la Salud (MPPS), ya que los de este último en los años 2002 y 2004 superan las cifras de la ONG por más del doble. Mención especial tienen los únicos tres años informados 
por el Ministerio Público (2005, 2006 y 2007), cuyas cifras superan en más del doble a las del MPPS. Esta información fragmentaria, inconsistente y contradictoria dificulta el análisis sobre el fenómeno.

Figura 1. Muertes en manos de los cuerpos de seguridad del Estado

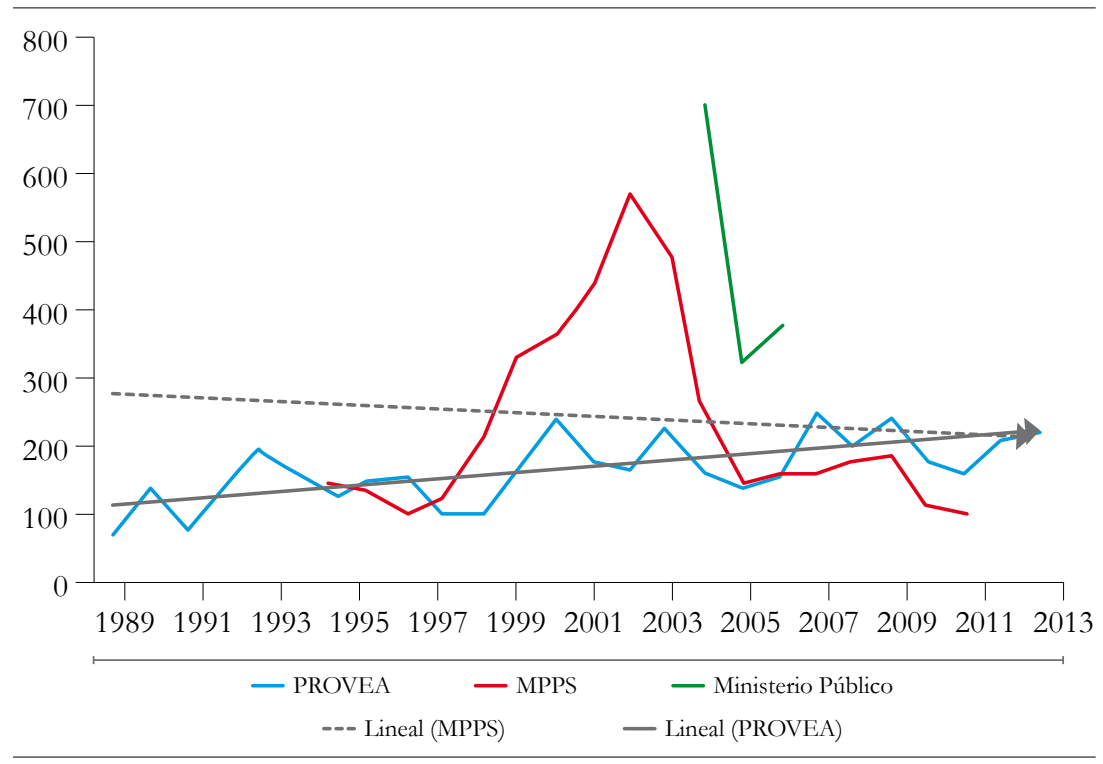

Fuente: elaboración propia.

Una herramienta adicional que es muy útil para hacer comparaciones entre países sobre este tema es el uso de la tasa de "muerte por intervención legal" pcmh. De un grupo de ocho países (Argentina, Brasil, Colombia, Costa Rica, Honduras, México, Perú y Venezuela), estudiados por Fondevila y Meneses (2014), Venezuela ocuparía actualmente el tercer lugar, con una tasa de 0,411 para el año 2011; el primer lugar lo tiene Honduras $(1,012)$, el segundo, Colombia $(0,553)$ y el cuarto, Brasil $(0,396) \cdot{ }^{11}$ Estos datos sugieren relaciones entre el aumento de tasas de homicidios nacionales y tasas de muertes debidas a intervención legal.

11 Los cálculos para Venezuela son propios y están basados en el Anuario de Mortalidad del MPPS y las proyecciones poblacionales del INE. Según estas mismas fuentes, la tasa para 2012 sería de 0,364 . Se hizo este procedimiento para actualizar la información del citado trabajo de Fondevila y Meneses (2014) que hacía el corte en el año 2010 (con una tasa de 0,649); para el resto de los países la fuente siguen siendo los referidos autores. 
Entre las explicaciones y reflexiones sobre la violencia policial, algunos autores han planteado que la legislación vinculada con el Sistema Penal, de corte garantista, afecta de alguna manera el comportamiento de la policía, quienes ante la pérdida de poder, discrecionalidad y certeza, reaccionan con un mayor uso de la coacción física (Antillano, 2012, 2014; Fondevila \& Meneses, 2014; Gabaldón, 1993; Zaffaroni, 1993). Esto se puede apreciar, por ejemplo, en la disminución de violaciones a la libertad personal, a la vez que aumentan las violaciones al derecho a la vida (Antillano, 2014; Romero, 2015). Por su parte, Batton y Wilson (2006) comentan cómo las críticas al comportamiento de la policía norteamericana ante disturbios y conflictos raciales durante las décadas del 60 y 70 tuvieron algún impacto en los cambios de esta institución, en especial respecto a la limitación del uso discrecional de la autoridad por parte de los funcionarios.

Partiendo de estos argumentos, desde una perspectiva interaccionista, pudiera plantearse lo siguiente: si la hipótesis de influencia de factores institucionales y sociales externos sobre las policías es válida, puede serlo también la hipótesis inversa: la influencia de la policía sobre sectores de la sociedad. Pudiera tener, entonces, la violencia policial algún impacto sobre la violencia social y delictiva.

Es importante tratar de contrastar las relaciones entre la violencia policial y las muertes de funcionarios policiales, no como relación lineal causa-efecto, sino como hipótesis de una concepción bélica entre bandos enemigos, en donde las fuerzas de seguridad "en cierta forma llevan la delantera a pesar de que se observen bajas de ambos lados" (Del Olmo, 1990, p. 225). Esta "guerra", tal como lo plantea Del Olmo, no debe entenderse de manera regular, ni siquiera como un simple escenario situacional de enfrentamiento policías-delincuentes, más bien se trataría: "por una parte, [de] la cacería de civiles, y por la otra, [de] la emboscada de miembros de los Cuerpos Armados" (1990, p. 225).

En este sentido, habría que preguntarse, ¿realmente ha habido en los últimos años un incremento significativo de la violencia policial? De ser así, ¿cuál es su influencia en la victimización de los funcionarios 
policiales? Esta hipótesis escapa en mucho del objeto del presente trabajo. Además, en la actualidad no se cuenta con datos suficientes para hacer los contrastes mínimos necesarios. Sin embargo, es una hipótesis explicativa sumamente sugerente que será considerada para futuras investigaciones.

Una vez evaluados los marcos teóricos, así como los contextos correspondientes, se procederá a presentar los resultados que buscan dar respuesta a las preguntas básicas sobre los casos de victimización por homicidio de los funcionarios de los cuerpos de seguridad en Venezuela.

\section{Los hallazgos de la investigación}

\section{1. ¿Dónde?}

En los cinco municipios estudiados, los casos se distribuyeron de la siguiente manera: 49 en Libertador (87,5\%), 6 en Sucre (10,7\%) y 1 en Chacao (1,8\%). Ni en Baruta ni en el Hatillo se reportaron casos durante el período en estudio. Si estos resultados se evalúan por tasas, el primer lugar lo tiene Libertador con una tasa de 2,36 homicidios de funcionarios por cada cien mil habitantes (hfpcm); el segundo, Chacao con una tasa de 1,4 hfpcm, y el tercero, Sucre con 0,9 hfpcm.

Respecto a las parroquias, podemos afirmar que de las 32 que tiene el $\mathrm{AMC}$, los casos en los que resultan víctimas de homicidios los funcionarios policiales se distribuyen en 22 de ellas. La parroquia con el porcentaje más alto de estos casos es Sucre con un 12,5\%, seguida de Antímano y Petare con un 8,9\% cada una; el tercer lugar lo comparten las parroquias Caricuao, Coche, El Junquito, El Recreo y Santa Rosalía con un 7\% de los casos cada una, es decir, que estas 8 parroquias concentran el $66 \%$ de todos los casos.

La mayoría de los casos $(83,9 \%)$ ocurrieron en sitios abiertos en plena vía pública, principalmente en avenidas $(38,3 \%)$ y calles $(29,79 \%)$. 


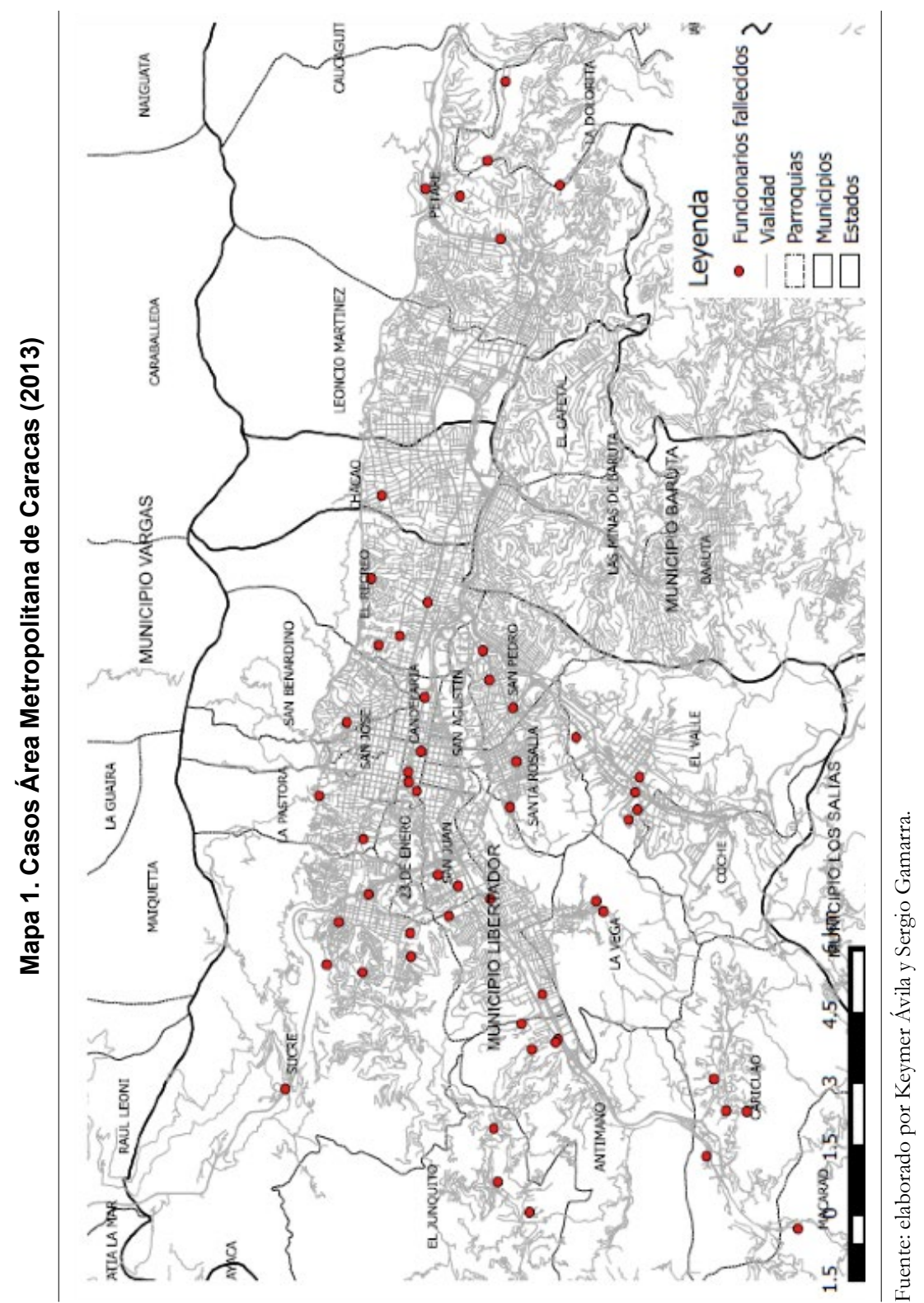




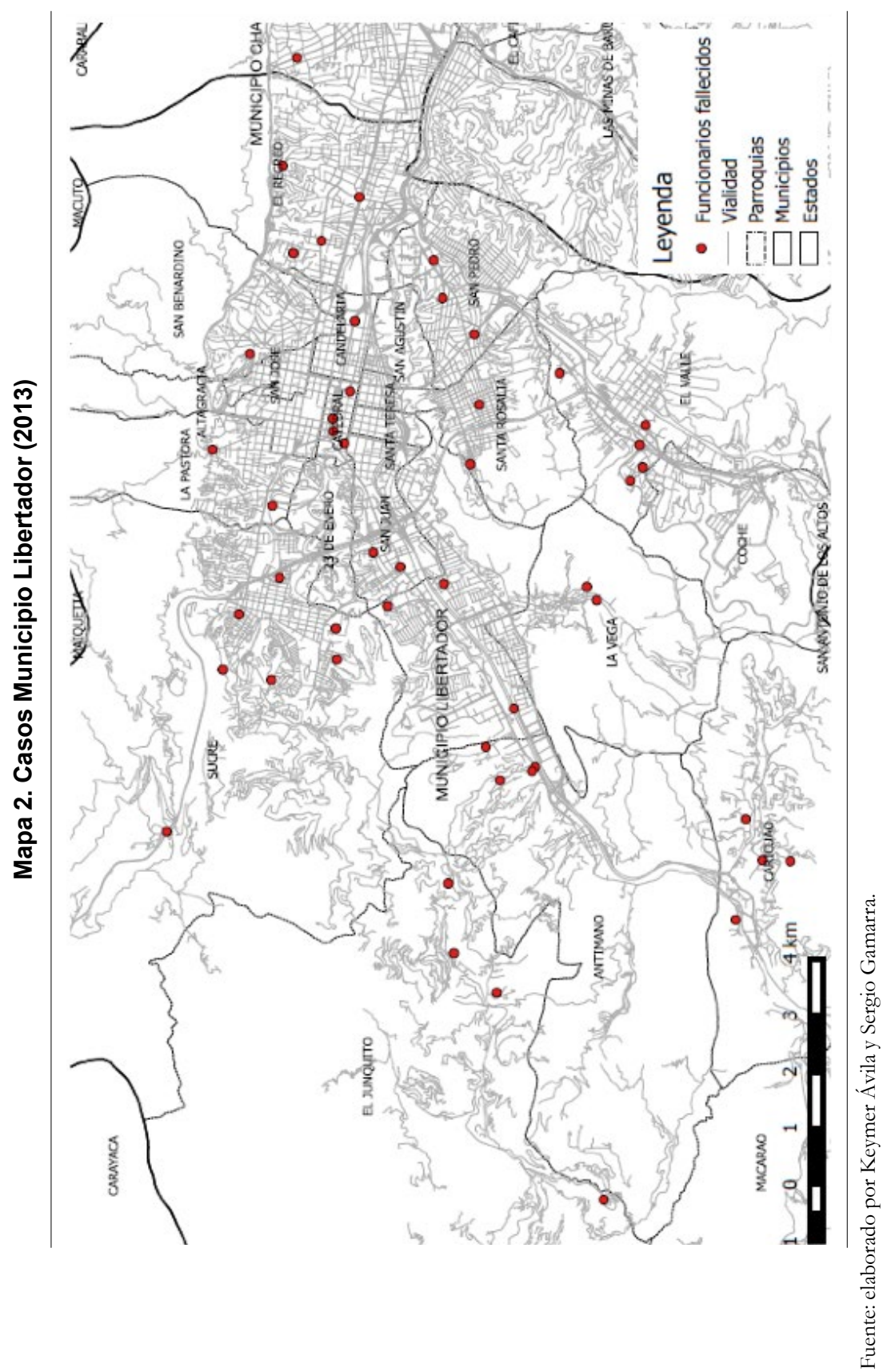




\section{2. ¿Cuándo?}

El mes en el que se cometieron el mayor número de casos fue diciembre con un $17,9 \%$, seguido de noviembre y febrero, que ocupan el segundo lugar con un $10,7 \%$ cada uno; el tercero lo ocupan los meses de mayo, agosto y septiembre con $8,9 \%$ cada uno. Los meses en los que hubo menos casos fueron julio y octubre con un 3,6\% para cada uno. Pareciera que en estos últimos meses se toma un impulso para el incremento abrupto del mes siguiente.

\section{Figura 2. Porcentaje de casos por mes}

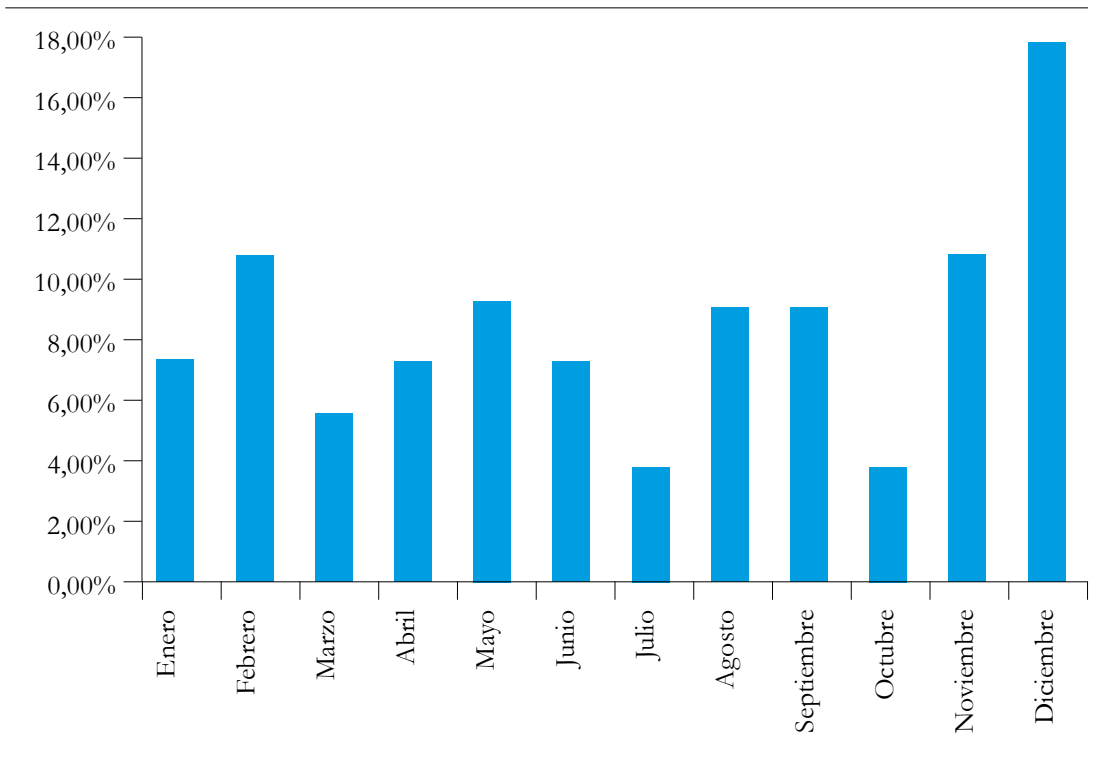

Fuente: elaboración propia.

En cuanto a los días de mayor riesgo, los domingos ocupan el primer lugar con un 28,6\% de los casos, seguidos de los sábados $(19,6 \%)$ y los lunes $(17,9 \%)$. Paradójicamente, los días viernes fueron los que reportaron el menor número de casos, llegando solo al 5,36\%. También de manera paradójica los días de quincena y los últimos de mes no arrojaron resultados significativos.

En cuanto a las horas, si dividimos el día en 6 períodos de 4 horas cada uno, los horarios más peligrosos para los cuerpos de seguridad 
en el AMC, de mayor a menor, son los siguientes: 1) de 4:00 a 7:59 $(28,57 \%)$ y de las $20: 00$ a 23:59 (26,79\%), en estas 8 horas ocurren más de la mitad de todos los casos; 2) de las 16:00 a 19:59 (14,3\%); 3) de las 00:00 a las 3:59 de la madrugada (12,5\%).

Figura 3. Porcentaje de casos por bloques de horario

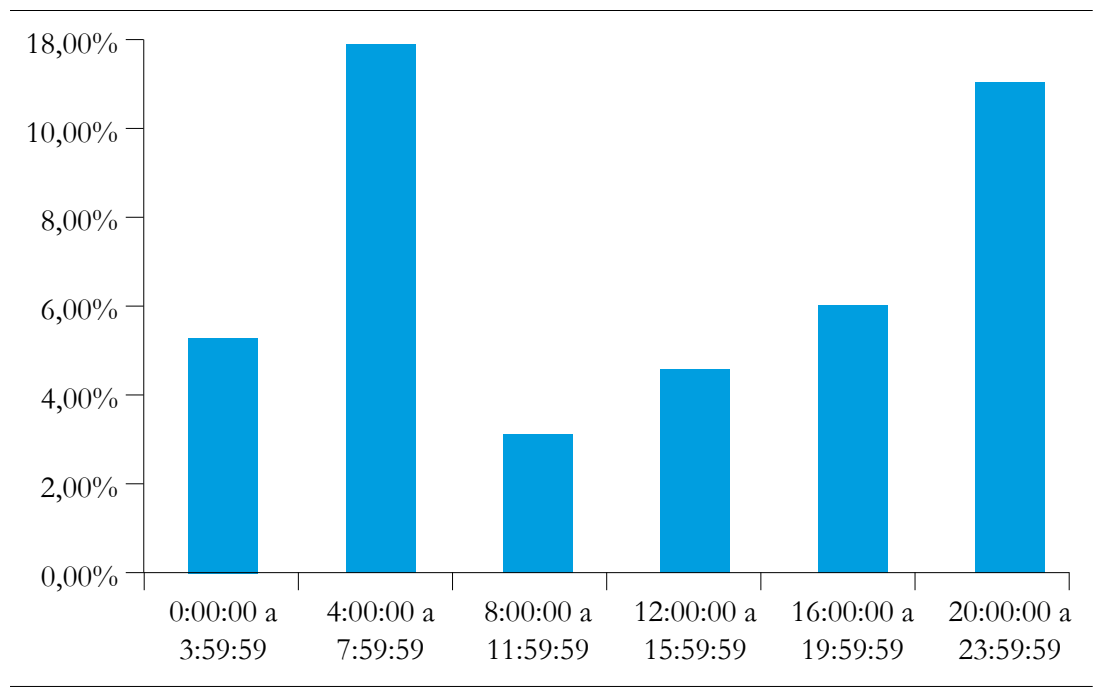

Fuente: elaboración propia.

\section{3. ¿Quiénes?}

\subsubsection{Las víctimas ${ }^{12}$}

Los 56 casos tienen un total de 62 víctimas fatales que son funcionarios de los cuerpos de seguridad del Estado, es decir, que la relación de víctima por caso no es de más de una persona, así es en un $92,9 \%$. La totalidad de las víctimas es plenamente identificada.

Del Olmo (1990) señaló que el 87\% de los funcionarios fallecidos de manera violenta en Caracas entre 1982 y 1986, fueron victimizados cuando circulaban solos. Esta tendencia mayoritaria se ha ratificado

\footnotetext{
12 Para analizar el perfil de las víctimas, en los pocos casos en los que éstas eran múltiples se tomó como referencia la que tuviese la mayor cantidad de información plasmada en el instrumento.
} 
-pero en menor medida- en esta investigación con casos del año 2013. Los funcionarios víctimas en su mayoría andaban solos (55,36\%) o con un solo acompañante $(19,64 \%)$, es decir que las víctimas constituían un grupo no mayor de 2 personas $(75 \%)$. Este es un dato clave para incrementar la seguridad personal de los funcionarios.

Considerando esta información, sería importante evaluar la posibilidad de que el grupo mínimo de funcionarios para patrullar en el AMC sea de cinco. Esto en modo alguno debe significar un incremento del pie de fuerza policial que, como ya se ha señalado, en Venezuela está muy por encima de los estándares; se trataría solo de una medida gerencial, administrativa, consistente simplemente en una distribución espacial y temporal del personal con el que ya se cuenta. Esto se ratifica cuando se analiza la cantidad de victimarios por caso.

En los 56 casos se detectaron unos 185 victimarios, teniendo un promedio de 3 victimarios por caso. En el 89,3\% de los casos los victimarios estaban conformados por un grupo de no más de cinco personas. La mayoría (39\%) actuaba en pareja.

Figura 4. Relación entre la cantidad de acompañantes de la víctima y la cantidad de victimarios

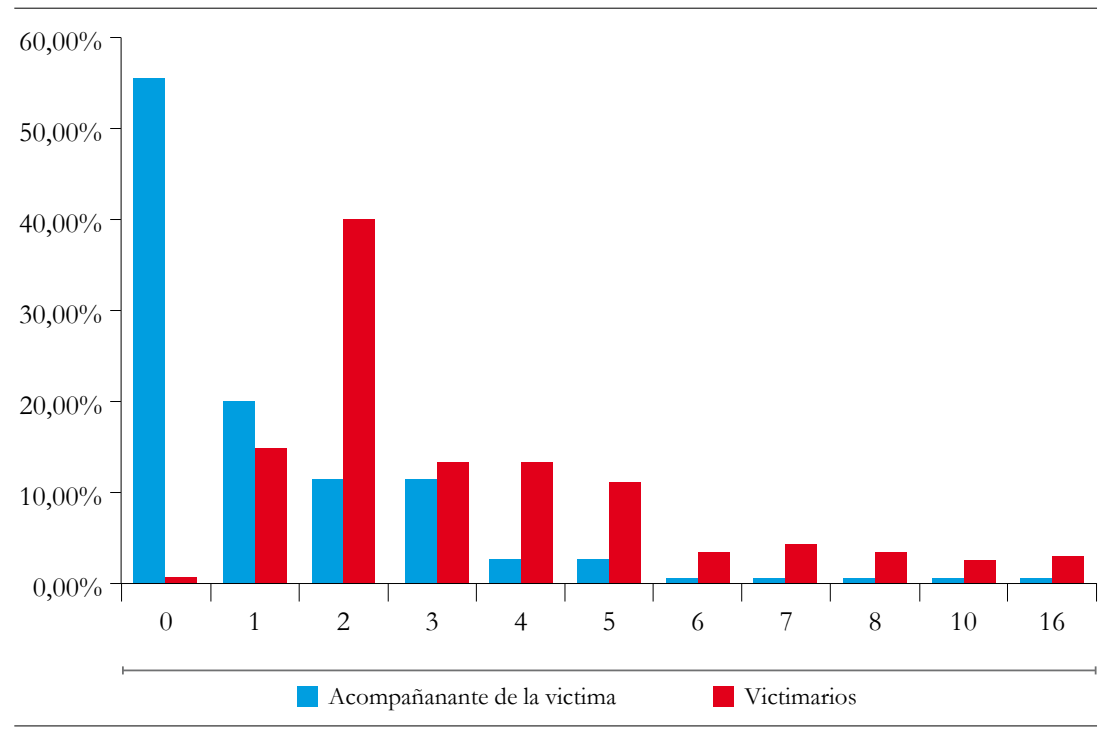

Fuente: elaboración propia. 
El 96,4\% de los funcionarios víctimas eran de sexo masculino, de estado civil soltero (80,4\%), y tenían una edad promedio de 30 años; es de advertir que el 70,45\% de ellos no llegaba a esta edad.

Cuando desagregamos a las víctimas por edades, estas varían entre los 18 y los 52 años. Los grupos mayoritarios son los siguientes: entre 18 y 22 (19,7\%); 23 y $27(23,2 \%) ; 28$ y $32(30,4 \%)$. Siendo entonces el grupo más vulnerable el que se encuentra entre los 23 y los 32 años, estos constituyen el 53,6\% de los casos.

\section{¿Se encontraban en ejercicio de sus funciones?}

Uno de los aspectos fundamentales para analizar la victimización de los funcionarios de los cuerpos de seguridad es saber si se encontraban o no prestando el servicio. Los hallazgos en este sentido fueron los siguientes: No 73,2\%; Sí 21,4\%; Sin información 5,4\%. Es decir, que siete de cada diez funcionarios fallecidos no se encontraban en ejercicio de sus funciones.

Estos resultados confirman lo planteado por Del Olmo (1990) cuando en su trabajo afirmaba que había una "tendencia a que los funcionarios mueran en otro tipo de situaciones, y no precisamente como resultado directo de enfrentamiento en actos delictivos. En este caso son más bien heridos" (p. 236). Más adelante comentaría Zaffaroni (1993) sobre este trabajo: "la muerte de la mayoría de los funcionarios no es resultado de un enfrentamiento, sino de emboscadas o ejecuciones" (p. 35).

En los casos analizados, solo en 4 (7,14\%) resultaron heridos otros funcionarios a parte de la víctima fatal. Este porcentaje coincide con los casos de legítima defensa policial y sería el indicador más claro de casos reales de enfrentamiento. Lo que confirmaría la tesis anteriormente citada.

\section{Identificación como funcionarios}

La identificación como funcionarios está muy vinculada con el punto anterior. Sobre este particular los resultados fueron los siguientes: 
un $67,9 \%$ no estaba uniformado y un $51,8 \%$ de los funcionarios no se encontraba identificado como tal (carnets, chaquetas, vehículos con insignias, etc.). Por lo que la identificación como funcionario de algún cuerpo de seguridad no pareciera haber sido un elemento significativo para su victimización.

Con los resultados sobre la prestación del servicio y la identificación como funcionarios por parte de las víctimas, pueden afirmase dos cosas: 1) El "segundo mito" (a los funcionarios los matan por su condición de policías, lo que sugiere un vínculo con el ejercicio de sus funciones), al menos en la mayoría de los casos analizados parece quedar sin sustento. 2) Las investigaciones norteamericanas sobre estos temas deben analizarse con sentido crítico, por una parte, porque están concentradas en la amenaza de perder la vida durante la prestación del servicio, y por otra, porque obedecen a un contexto muy distinto al venezolano y, en consecuencia, su alcance pudiera ser bastante limitado. Sirva el ejemplo ya citado de Kaminski y Martin (2000), quienes encontraron que un $69 \%$ de los policías habían sido víctimas de ataques violentos durante la prestación del servicio; sus resultados parecieran ser inversos a los nuestros, reflejan dos realidades diferentes. Pueden ser de utilidad para los supuestos en los que los funcionarios efectivamente estén prestando el servicio, pero los mismos representan la minoría de los casos analizados en este estudio.

\section{Experiencia}

En solo el 50\% de los casos se pudo obtener información acerca de la cantidad de años de servicio de los funcionarios. De estos casos, el $64,3 \%$ tenían menos de 4 años de servicio y $21,4 \%$ tenía menos de un año en la institución; este último grupo es el mayoritario. Al evaluar los datos, se puede apreciar claramente cómo la relación entre los años de experiencia y la victimización es inversamente proporcional: a menor tiempo de servicio mayor victimización. ${ }^{13}$

\footnotetext{
13 La excepción fueron 2 casos (7,14\%) en los que las víctimas tenían 17 años de servicio. Ninguno cumplía con el perfil general de los casos estudiados.
} 
Figura 5. Años de servicio de la víctima

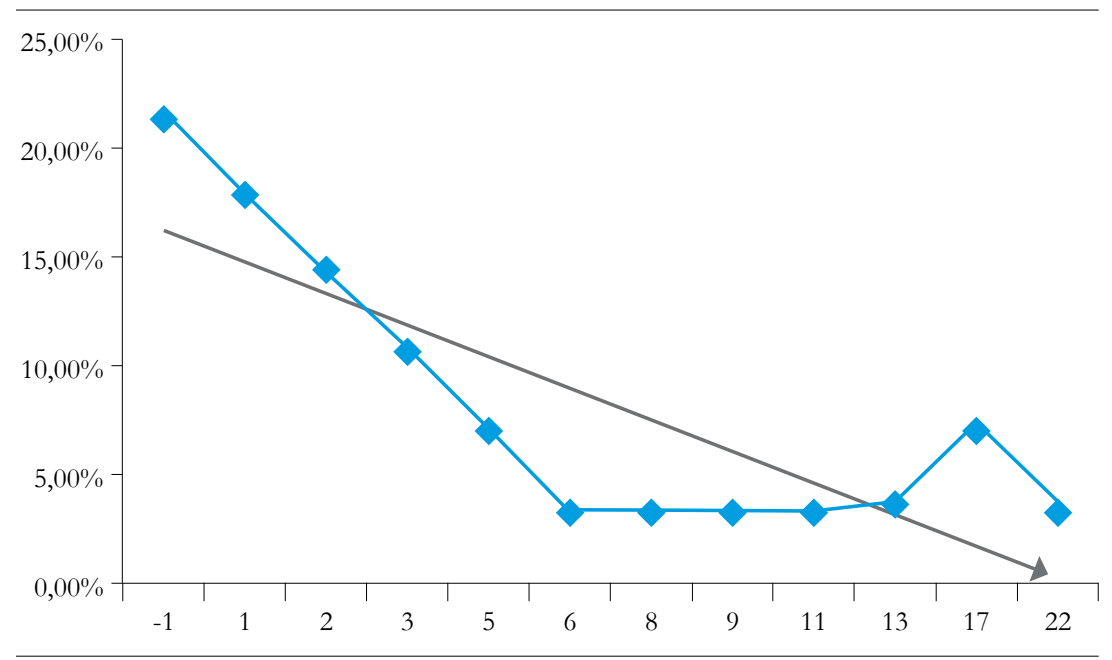

Fuente: elaboración propia.

Esta tendencia coincide cuando se analizan los rangos dentro de la carrera policial. El 81,7\% de los casos contaba con información detallada sobre los rangos. De estos, el $54 \%$ de las víctimas pertenecían al rango más bajo del nivel operacional (oficiales, detectives y soldados), seguidos por el segundo rango del mismo nivel, con un $23 \%$, sumando así un 77\% de los casos. En este sentido, es clara la relación entre el inicio de la carrera y el riesgo de victimización; en la medida que el funcionario adquiere mayor experiencia y logra sus asensos, disminuye su vulnerabilidad.

Estos resultados nos dan un segundo gran contraste con las investigaciones estadounidenses que, como se ha mencionado, señalan que el riesgo de muerte violenta no se limita a los oficiales inexpertos o descuidados: el 42\% de los oficiales asesinados tenía más de 10 años de experiencia (Batton \& Wilson, 2006); en nuestros casos solo el $17,85 \%$ cumplía con este perfil.

Cuerpos de seguridad al cual pertenecían

Del Olmo (1990) explica que durante los años ochenta en Caracas, los funcionarios fallecidos no se concentraban en un solo cuerpo, 
sino que se distribuían entre la Policía Metropolitana (PM) (26,4\%), la Dirección Nacional de Servicios de Inteligencia y Prevención (DISIP) $(22,3 \%)$, los vigilantes privados $(20,9 \%)$, la Guardia Nacional (GN) $(10,1 \%)$, la Policía Técnica Judicial (PTJ) (8,8\%), la Fuerza Armada $(6,1 \%)$ y otros $(5,4 \%)$. En esa década no existían las policías municipales, las cuales habían sido disueltas en el país unos 30 años atrás; estas renacerán a partir de 1990 como resultado del proceso de descentralización y de la elección directa y universal de los alcaldes (Antillano, 2007; Márquez \& Castillo, 2002; Núñez, 2006). Por las respectivas leyes que las rigen, la PTJ pasó a denominarse CICPC en el año 2001, y la GN a partir de 2008 es llamada GN Bolivariana (GNB); la PM fue liquidada por mandato de la Ley Orgánica del Servicio de Policía y del Cuerpo de PNB de 2009, y la DISIP fue transformada al año siguiente en el Servicio Bolivariano de Inteligencia Nacional. De esta manera, la PNB, las policías municipales, el CICPC y la GNB pasarán a ocupar los espacios de la PM, la DISIP y posiblemente el de los vigilantes privados ${ }^{14}$ en el AMC.

Durante 2013 el cuerpo policial que más víctimas aportó fue la PNB con un 33,9\% de los casos, seguido de las policías municipales con $17,9 \%$, ocupando el CICPC el tercer lugar con 16\% de los casos. En el AMC la única policía estadal es la de Miranda, que tiene competencias para la prestación del servicio en los municipios Sucre, Baruta, Chacao y el Hatillo. Además, no se reportaron casos de policías estadales fallecidos en el AMC; esto posiblemente se deba al despliegue que la PNB hace sobre este territorio y que trae como consecuencia que la Policía de Miranda no tenga presencia en estos 4 municipios para dedicarse a los restantes 17 municipios de su Estado. Así entonces, estos resultados no pueden trasladarse a nivel nacional, en donde la PNB no tiene todavía un despliegue pleno. La GNB ocupó el cuarto lugar (14,3\%), seguido de funcionarios del Ejército (12,5\%), si se suman ambos componentes estos constituirían el 26,8\% de los casos, ocupando el segundo lugar.

\footnotetext{
14 Estos últimos no forman parte de nuestro estudio.
} 


\section{Lugar de domicilio o residencia}

Solo el 28,6\% de los casos ocurren cerca al lugar de residencia de la víctima. Sería importante estudiar estos últimos, ya que es posible que exista algún tipo de trabajo de seguimiento previo de la vida cotidiana de los funcionarios para hacerles una emboscada y atacarlos.

Es interesante el contraste de estos resultados con los obtenidos por la ENV 2009, según la cual el 71,6\% de los casos de homicidios comunes ocurren en la misma parroquia en la que vivía la víctima. En la presente investigación esta coincidencia baja unos 30 puntos, para llegar a un 41,1\%. Al parecer los civiles corren más peligro de ser asesinados en su propia parroquia que los funcionarios de los cuerpos de seguridad.

\subsubsection{Los victimarios ${ }^{15}$}

En los expedientes estudiados, el 80\% de los victimarios fueron identificados (148 de un total de 185). El número de victimarios puede variar entre una persona y 16, aunque este último caso fue único. Ya se mencionó que la cantidad promedio de victimarios por caso es de 3 , en esta sección se caracterizarán los mismos.

El 96\% de los victimarios es de sexo masculino, de estado civil soltero (52,8\%), y tienen una edad promedio de 25 años. Es de advertir que el $66 \%$ de ellos no había llegado para el momento del hecho a esa edad.

Respecto a la nacionalidad en el 86,8\% de los casos son venezolanos, el resto no presentó información sobre la nacionalidad y no se encontraron casos de victimarios extranjeros, por lo que la tesis de rasgos xenófobos a la que se ha hecho referencia en secciones anteriores, que hemos denominado como el "tercer mito" (los victimarios de los

\footnotetext{
15 Para analizar el perfil de los victimarios en los casos en los que estos eran múltiples se tomó como referencia al "victimario principal". Para esta selección se escogió al que haya tenido el mayor protagonismo en el homicidio y, que a su vez, tuviese la mayor cantidad de información plasmada en el instrumento.
} 
funcionarios fallecidos son paramilitares colombianos), al menos en el año y el lugar objeto del presente estudio, no encuentra sustento.

Cuando desagregamos a los victimarios por edades, estas varían entre los 17 y los 39 años; los grupos mayoritarios son los siguientes: entre $17^{16}$ y 22 (61,2\%); 23 y 27 (22,46\%); 28 y 32 (12,26\%). Los victimarios son en promedio 5 años más jóvenes que sus víctimas; en la medida en que se acercan a los 32 años, el número de victimarios disminuye, al contrario de lo que sucede con los funcionarios víctimas.

Figura 6. Edades de víctimas y victimarios

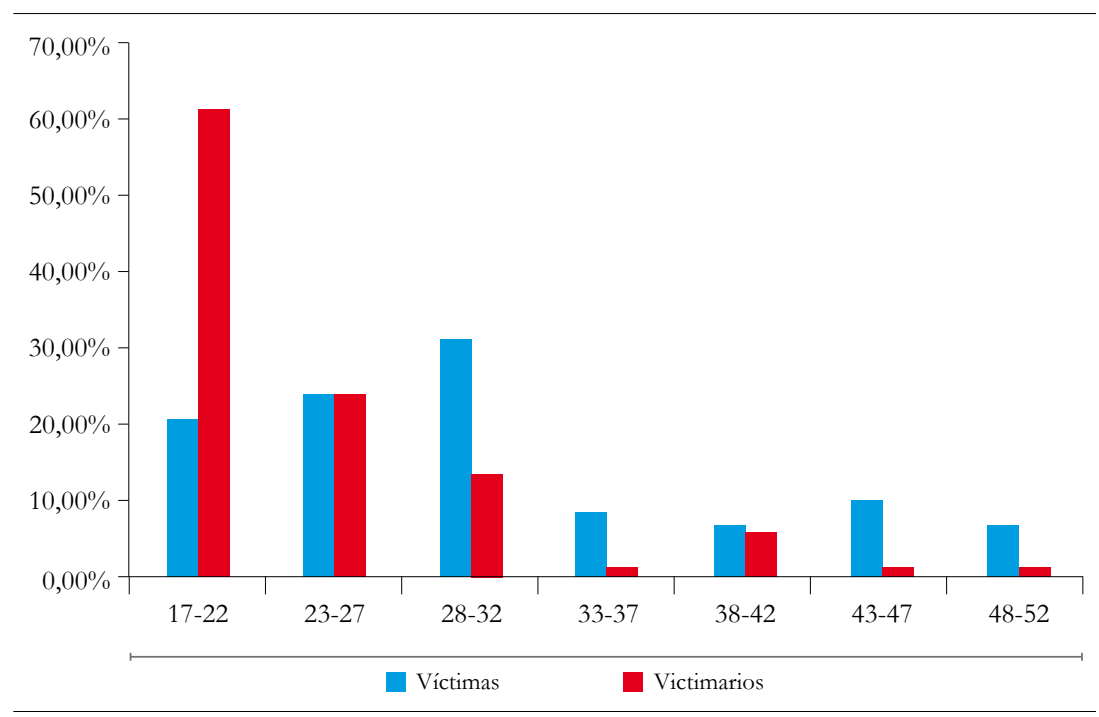

Fuente: elaboración propia.

\section{Profesión u oficio}

Solo en un 51,8\% de los casos se halló información respecto a la profesión u oficio de los victimarios. Dentro de estos se distinguen, ordenados de mayor a menor porcentaje, las ocupaciones siguientes: 1) Funcionarios de cuerpos de seguridad del Estado (31\%); 2) obreros, albañiles, artesanos y pintores $(24 \%) ; 3)$ estudiantes $(14,8 \%)$; 4 ) ven-

\footnotetext{
16 De 17 años solo hubo 3 casos, lo que representa apenas un 6\%; por debajo de esa edad no se encontró caso alguno.
} 
dedores o almacenistas (10,4\%) y microtraficantes de drogas (10,4\%); 5) Asaltantes, indigentes y mototaxistas (3,4\% c/u) (un solo caso c/u).

Lo que más llama la atención -y preocupa a la vez- de estos resultados es que un 31\% de los casos son perpetuados por funcionarios de los cuerpos de seguridad del Estado contra colegas suyos. Esto en parte puede obedecer a que en estos casos los funcionarios victimarios son mucho más visibilizados respecto a los de otros oficios. Veamos a continuación sus perfiles.

De este 31\% de los casos, 44,4\% 9); se encontraba en ejercicio de sus funciones, estaban uniformados e identificados como oficiales; el otro $22,2 \%$ no lo estaba, y un 33,33\% no proporcionó información sobre estos aspectos.

El 33,3\% de los funcionarios victimarios pertenecían al ejército; 33,3\% a la PNB, mientras que el CICPC, las policías municipales y los escoltas representaron cada uno un 11\%. El 77,8\% de los funcionarios victimarios pertenecían a los niveles operativos más bajos de sus respectivas carreras. La no representación de las policías estadales tiene la misma explicación que se dio en el caso de su no representación en los funcionarios víctimas.

Es de advertir que este no es un fenómeno nuevo. Ya Del Olmo (1990) en su citado trabajo describió que a mediados de la década de los ochenta, aproximadamente, un $20,2 \%$ de los funcionarios fallecidos en Caracas fueron victimizados por otros funcionarios. Esto abre la posibilidad a nuevas hipótesis para ser analizadas en futuras investigaciones.

Finalmente, se considera necesario hacer mención de los microtraficantes y asaltantes que, al contrario de lo que dice el sentido común y los prejuicios populares e institucionales, no ocupan los primeros lugares entre las ocupaciones de los victimarios, si bien debe advertirse que en el expediente no solo hay información institucional, sino también testimonios que pueden estar cargados de intereses y prejuicios particulares que afecten estos resultados; estos son datos 
que no deben sobreestimarse pero tampoco subestimarse. También resultó interesante que los "estudiantes" ocuparon el tercer lugar en la escala.

\section{Lugar de domicilio o residencia}

Respecto a la relación existente entre el domicilio o residencia del victimario y la víctima solo en un 3,8\% (2 casos) coinciden los lugares de residencia de ambos. Por lo tanto se puede afirmar que el "sexto mito" (los matan porque viven en los mismos barrios que sus victimarios), no encuentra sustento en esta investigación, y pareciera ser una variable poco relevante para la explicación de estos eventos.

En contraste, en donde sí parece haber un mayor vínculo es entre el lugar de residencia del victimario y el lugar del hecho (Urbanización, Barrio o Sector): este fue de un 32\%.De esta manera, se puede afirmar que aproximadamente un 30\% de los casos ocurren cerca de la vivienda de la víctima (tal como se explicó en la sección correspondiente) y otro $30 \%$ ocurren cercanos a la vivienda del victimario. Ambos datos son relevantes a efectos de establecer políticas de prevención, así como de investigación penal para estos casos. Parecieran, además, fortalecer la hipótesis de las emboscadas.

\section{4. ¿Cómo?}

\subsubsection{Uso de armas de fuego}

\section{Víctimas}

En 94,6\% de los casos las víctimas fueron heridas con armas de fuego. Este es un porcentaje mayor en comparación con el de los casos de homicidios comunes (79,5\% ENV 2009; 90,5\% CICPC) y del estimado por Kraus, en el contexto estadounidense, para los homicidios relacionados con el trabajo (77\%), lo que indica que los policías mueren más por armas de fuego que el resto de la población. 
El 62,5\% de los funcionarios asesinados portaba armas de fuego. Si, tal como hemos demostrado, siete de cada diez víctimas no se encontraban prestando el servicio, ¿por qué estaban armadas entonces?

En la cultura policial, el argumento es que los funcionarios de los cuerpos de seguridad tienen esta cualidad las 24 horas del día, razón por la cual deben siempre andar armados, aun estando fuera de servicio (cuarto mito), pero ¿existen estudios empíricos que verifiquen la justificación de esta "tradición" indiscutible en esos espacios?

El dato preciso es que $58,5 \%$ de los funcionarios víctimas que no se encontraban en ejercicio de sus funciones se encontraban armados, es decir, que a más de la mitad de ellos no les sirvió de nada portar el arma fuera de las horas de servicio, y posiblemente esa misma situación haya promovido su muerte. De alguna manera, se verifica la hipótesis de Bandeira (2011) y Bandeira \& Bourgois (2006), según la cual el arma de fuego no es garantía de protección, sino todo lo contrario. Sirvan los datos siguientes como ejemplos: a) 25\% de los funcionarios victimas que no se encontraban en funciones y portaban su armamento provocaron previamente a su victimario con alguna amenaza real contra su vida; b) lo anterior constituye un $60 \%$ de los casos en los que hubo este tipo provocación por parte de los funcionarios fallecidos; c) solo en un 5,4\% de los casos totales (3) el funcionario víctima logró matar a su victimario, ambos perecieron el mismo día; d) en el 54\% de los casos en los que las víctimas se encontraban armadas, sus armas fueron robadas por sus victimarios; e) solo en un $28,6 \%$ de los casos la víctima se encontraba desarmada. ${ }^{17}$

Con estos resultados el cuarto mito (los funcionarios de seguridad deben andar armados también fuera de servicio porque el arma le brinda más seguridad) se presenta como discutible, y en esta investigación no encuentra sustento. Estos elementos deben ser considerados seriamente para un debate, basado en datos concretos, sobre el impacto real de que los funcionarios estén armados fuera de servicio.

17 Un 8,93\% de los casos no aporto información alguna sobre este particular. 


\section{Victimarios}

El 77,4\% de los victimarios portaba arma de fuego; solo en 2 casos utilizaron armas blancas $(3,8 \%)$ y en uno un objeto contundente $(1,9 \%)$; en un $15 \%$ no se halló información sobre este particular.

De los casos en los que el victimario portaba arma de fuego, el 75,6\% de las mismas eran armas cortas y 4,9\% armas largas; en un 19,5\% no se encontró información al respecto. Un 9,8\% era de origen orgánico. Con estos datos puede afirmarse que al menos un $10 \%$ de las armas con las que los funcionarios son asesinados tienen un origen lícito y provienen de los propios cuerpos de seguridad del Estado.

Cuando se contrasta el armamento que tenían víctimas y victimarios se observa que las primeras tenían un porcentaje más alto de armas largas $(5,7 \%)$ que los segundos (4,9\%). En estos escasos episodios se trataba de víctimas y victimarios militares. En resumen, en la mayoría de los casos ambos actores portaban pistolas. De esta manera, el quinto mito, asociado a las muertes de funcionarios de los cuerpos de seguridad (los delincuentes están mejor armados que los policías) en este estudio no encontró sustento alguno.

\subsubsection{Heridas}

\section{Víctimas}

Como ya se señaló, el $94,6 \%$ de sus muertes fueron ocasionadas por el uso de armas de fuego, solo un 3,6\% fueron por armas blancas y $1,8 \%$ por objetos contundentes. De los casos en los que hubo uso de armas de fuego, la cantidad de disparos que recibió la víctima varía entre 1 y 56 ; el promedio por caso es de unos 7 .

Las partes del cuerpo lesionadas más afectadas son la cabeza $(35,9 \%)$ y el tronco $(28,7 \%)$. Estos resultados evidencian una clara intencionalidad por parte del victimario de causar la muerte y posiblemente una ventaja situacional respecto a esta. 


\section{Victimarios}

En el caso de los victimarios, solo el 18,9\% fue herido por armas de fuego, ninguno resultó lesionado por armas blancas u objetos contundentes. De los casos en los que hubo victimarios heridos por armas de fuego, la cantidad de disparos que recibieron varían entre 1 y 21, de los cuales el promedio por caso es de 7.

Las partes del cuerpo lesionadas más afectadas son el tronco $(45,8 \%)$ y la cabeza $(20,8 \%)$. Se aprecia así un orden de afectación corporal inverso entre víctimas y victimarios: el área de la cabeza es la más vulnerable de los funcionarios, mientras que la de los victimarios es el tronco.

Un 24,5\% (13) de los victimarios identificados murieron. De estos casos, el 38,5\% murió durante el enfrentamiento con el funcionario policial o en el transcurso de ese mismo día, mientras que más de la mitad $(53,9 \%)$ pereció en un momento posterior.

Estos datos constatan la tesis de Monsalve (2006), según la cual la policía, en los casos en los que resultan asesinados sus funcionarios, aplica directamente el castigo a los responsables, que no es otro que la muerte. El caso lo resuelve de manera rápida la propia agencia sin intervención de otras instituciones.

Cuando se indaga sobre los casos en los que resultan fallecidos tanto la víctima como alguno de sus victimarios, un 53,8\% de estos casos son motivados por razones distintas al desempeño de la función policial. Las relaciones generales entre víctima y victimario, así como los móviles de estos casos, serán desarrollados en detalle a continuación.

\section{5. ¿Por qué?}

\subsubsection{Relaciones entre víctima y victimario}

En un 28,3\% de los casos existía algún vínculo o al menos se conocían la víctima y el victimario. ${ }^{18}$ En un $20,8 \%$ de estos eventos, existía entre

18 En un 52,8\% de los casos en los que está identificado el victimario, éste no tenía ningún 
ellos algún tipo de conflicto: a) conflictos de vecindad (36,4\%); b) discusiones $(27,3 \%), c)$ conflictos conyugales, económicos, denuncias previas de la víctima en contra del victimario, venganzas $(9,1 \% \mathrm{c} / \mathrm{u})$. Esto suma un $72,8 \%$ de casos en los que el conflicto generador del hecho no tiene que ver directamente con la prestación del servicio de policía, lo que ratifica los resultados obtenidos cuando se evaluó este punto en particular (segundo mito).

\subsubsection{Móvil de los hechos}

Entre los principales móviles detectados se encontraron: a) conflicto vinculado a actividades criminales $53,6 \%$; b) conflictos interpersonales ${ }^{19} 23,2 \%$; d) sin motivaciones aparentes / motivos fútiles e innobles $12,5 \%$; e) Legítima defensa 7,14\%; f) accidentes con armas de fuego / balas perdidas 3,6\%. Es decir, que en un 39,3\% de los casos la victimización de los funcionarios, nuevamente, no aparece vinculada directamente al ejercicio de sus funciones, esto se suma a los resultados de secciones anteriores que cuestionan al segundo mito.

Entre las actividades criminales se destacan los robos (62,5\%). En los robos de los que son víctimas los funcionarios fallecidos, el primer lugar lo toman sus armas de fuego $(54,3 \%)^{20}$, seguido de sus motos $(14,3 \%)$ para sumar ambos un $68,6 \%$ de los casos de robo, lo que representa un $42,9 \%$ de los casos totales. El tercer lugar lo ocupa el robo de vehículos $(8,6 \%)$ y de otras pertenencias, como celulares y laptops $(8,6 \%)$.

A pesar de estas cifras, resultaría muy simplista y engañoso afirmar que el robo sea la principal razón de estos casos. En primer lugar, porque en ocasiones el conflicto comienza como interpersonal y luego deviene en un hurto al cadáver, en donde el arma sería una

tipo de vínculo o relación previa con la víctima; en un 18,9\% de los casos no se encontró información sobre este particular.

19 Para estas primeras dos categorías se tomaron como referentes las tipologías de la ONUDD para estudiar los homicidios intencionales.

$20 \quad 33,9 \%$ de los casos totales. 
especie de trofeo. En la investigación no queda claro si el robo del arma es el motivo del ataque en contra de la vida del policía, o es una consecuencia de su deceso, que pudo haber sido motivado por otras razones. En segundo lugar, porque en el presente trabajo no se explora el ámbito cultural de los victimarios, en donde la dimensión simbólica de matar a un policía puede ser bastante significativa. La tensión, o en su defecto, el complemento, entre lo instrumental y lo expresivo de estos casos debe ser objeto de próximas investigaciones. De lo que sí no queda en duda es que el robo del arma a las policías incrementa la inseguridad de todos, potenciando el poder bélico de grupos delictivos.

\section{Reflexiones finales}

\subsection{El caso tipo}

Con base en los resultados analizados, podría considerarse como un caso típico de victimización por homicidio de funcionarios de los cuerpos de seguridad en el AMC el siguiente: Pablo tiene 30 años, se encuentra en una avenida del municipio en donde vive, pero fuera de su parroquia de residencia, carga encima su pistola asignada, es domingo y son las 4:00 am. Él es oficial de la PNB, tiene menos de un año en la institución, pero en ese momento no se encuentra prestando el servicio, razón por la cual no está ni uniformado, ni identificado como policía. Es atacado por dos sujetos, de unos 25 años, sin ocupación conocida; ellos también están dentro de su municipio, pero fuera de su parroquia de residencia; ambos andan armados con un par de pistolas. Los atacantes le disparan 7 veces en la parte superior del cuerpo, incluyendo la cabeza. Pablo no tiene chance de reaccionar, muere en el acto. Los victimarios toman del cadáver el arma de reglamento. No queda claro si el móvil del hecho fue el robo del arma o tuvo alguna otra razón.

\subsection{Desmitificaciones circunstanciales}

Del Olmo (1990) estaba convencida de que "en la actualidad la primera tarea de la criminología crítica de América Latina es la de investigar 
nuestra realidad" y por ello desde 1979 se esforzó por “contribuir a la reflexión y a desmitificar toda una serie de supuestos" (p. 5). En este trabajo se ha hecho el intento por seguir esas líneas. Se señalaron 6 mitos que giran mediáticamente en torno a los casos de homicidios de funcionarios de los cuerpos de seguridad en Venezuela, los cuales no encontraron sustento en la presente investigación. Veamos uno por uno:

Primer mito: el asesinato de funcionarios de seguridad es un fenómeno de los últimos tiempos. Falso. Desde los años ochenta se había analizado este fenómeno, que ya para esa época no era excepcional ni novedoso. Es de advertir que el hecho de que el primer y único estudio que se ha hecho sobre este tema sea de esa década no significa que no existiese antes.

Segundo mito: Los matan por su condición de policías, lo que sugiere un vínculo con el ejercicio de sus funciones. Falso. El $73 \%$ de los oficiales fallecidos no se encontraban en ejercicio de sus funciones; un $67,9 \%$ no estaba uniformado y un $51,8 \%$ no se encontraba identificado de manera alguna como funcionario. En los casos en los que se pudo detectar un conflicto previo entre víctima y victimario, en el 72,8\% de estos el conflicto generador del hecho no se vinculaba con la prestación del servicio de policía, y en un $39,3 \%$ de los casos el móvil tampoco parece encontrarse vinculado con tales funciones.

Tercer mito: Los victimarios de los funcionarios fallecidos son paramilitares colombianos. Falso. La nacionalidad de los victimarios fue la venezolana en el 86,8\% de los casos en los que pudo verificarse la nacionalidad. El resto de los victimarios no presentó información sobre la nacionalidad, ni se encontraron casos de victimarios extranjeros.

Cuarto mito: Los funcionarios de seguridad deben andar armados aún fuera de servicio porque el arma les brinda más seguridad. El 58,5\% de los funcionarios víctimas que no se encontraban en ejercicio de sus funciones se encontraban armados; sin embargo, esto no le sirvió como protección; por el contrario, posiblemente esa 
situación haya promovido su muerte. Un $25 \%$ de estos funcionarios provocaron previamente a su victimario con alguna amenaza real contra su vida. Lo anterior constituye un $60 \%$ de los casos en los que hubo este tipo provocación. Solo en un 5,4\% de los casos totales el funcionario víctima logró matar a su victimario y ambos perecieron el mismo día. Estos datos parecieran indicar que el porte de armas fuera de las horas de servicio no protege a los funcionarios, sino que los expone. Sería interesante contrastar estos resultados con casos en los que los funcionarios sí lograron salvar su vida, gracias al porte de su arma fuera de servicio, así como los móviles de los mismos, para evaluar la utilidad y el impacto real de esta tradición. Por otra parte, habría que considerar que dentro de los elementos robados a los funcionarios fallecidos, las armas de fuego representan el primer lugar (54,3\%), lo que constituye un 33,9\% de los casos totales. Adicionalmente, el 10\% de las armas con las que son asesinados los funcionarios provienen de los propios cuerpos de seguridad. Por todo ello habría que evaluar hasta qué punto portar el arma de fuego fuera de servicio termina siendo un elemento que no solamente incrementa la vulnerabilidad del funcionario, sino que, además, se convierte en una fuente de provisión de armas para la delincuencia, incrementando la inseguridad de la ciudadanía en general.

\section{Quinto mito: Los delincuentes están mejor armados que los} policías. Falso. Cuando se contrasta el armamento que tenían las víctimas y los victimarios se observa que las primeras tenían un porcentaje más alto de armas largas (5,7\%) que los segundos (4,9\%). En estos escasos episodios se trataban de víctimas y victimarios militares. En la mayoría de los casos tanto víctimas como victimarios portaban pistolas y su armamento era similar.

\section{Sexto mito: Los matan porque viven en los mismos barrios que} sus victimarios (los delincuentes). Falso. La relación existente entre el domicilio o residencia del victimario y la víctima solo coincidió en 2 casos (3,8\%). Lo que resulta estadísticamente insignificante. Más posibilidad tiene un civil de ser asesinado en su parroquia de residencia $(71,6 \%)$ que un funcionario de los cuerpos de seguridad $(41,1 \%)$. 
Estas desmitificaciones, excepto la primera, son para los casos ocurridos en el AMC durante el año 2013, no pretenden tener un carácter universal ni atemporal, pero sí aportar información verdadera para una toma de decisiones racional y bien administrada.

\subsection{Comentarios generales}

1) Si siete de cada diez funcionarios fallecidos no se encontraban ejerciendo sus funciones, ni se encontraban uniformados ni identificados como tales, y un número considerable de los conflictos y los móviles del hecho no se encuentran vinculados con la naturaleza del servicio, ¿deberían considerarse realmente estos casos como muerte de funcionarios de cuerpos de seguridad? ¿Hasta qué punto no han contribuido intereses mediáticos, políticos y corporativos para construir estos casos como tales? ¿La mayoría de los casos analizados no deberían ser considerados como casos comunes de homicidio?

2) Del análisis de estos casos es lógico concluir que el problema real es la violencia generalizada, es decir, las altas tasas de homicidios que tiene Venezuela y que vienen en aumento progresivo desde hace décadas. Están muriendo de manera violenta no solamente quienes trabajan en la policía, sino también personas de oficios diversos. Seguramente, si se estudian casos de taxistas, obreros, prostitutas, desempleados o indigentes víctimas de homicidios en la Venezuela actual, se encontrarán incrementos significativos, pero su poder de reclamo social, el impacto mediático y los niveles de alarma que estos sectores pueden generar son mucho menores que los que producen los integrantes de los cuerpos de seguridad.

3) Con lo anterior no se quiere decir en modo alguno que la labor de los cuerpos de seguridad no sea de alto riesgo; el problema es que estos casos apenas llegaron a un 30\%. De legítima defensa policial solo se hallaron 4 casos $(7,14 \%)$. Es para el análisis de estos casos que son de utilidad las investigaciones anglosajonas consultadas que tienen un enfoque más organizacional y técnico sobre el tema policial.

4) Respecto a lo interno de la institución policial: a) actualmente, Venezuela se encuentra por encima de la tasa de encuadramiento 
policial, por lo que no hacen falta más policías. Lo que se necesita es una mejor policía, ya que el problema no es la cantidad, sino la calidad; b) la idea sobre el número de funcionarios idóneo para patrullar o hacer rondas merece ser debatida considerando la información que se ha levantado; c) la captación, entrenamiento, supervisión y control de los nuevos policías debe ser evaluado y mejorado; d) el policía debe estar en permanente estado alerta y no sobreexponerse en ninguna circunstancia, ya sea que esté prestando o no el servicio; e) se considera pertinente también el debate sobre la posibilidad de que el policía que no está en servicio deje el arma en su lugar de trabajo, en el parque de armas respectivo, no solo por su seguridad, sino por la seguridad de todos. A su vez, estas instalaciones deben estar bien resguardadas; f) es fundamental un estricto control y supervisión de las armas y municiones de la institución policial y militar: dotación, uso, justificación y fiscalización de la cantidad que se les otorga, marcaje de municiones, etc.

5) En el presente estudio no se verificaron las versiones oficiales sobre conspiraciones políticas de entes extranjeros para asesinar a funcionarios policiales. Se considera que cuando se lanza a la opinión pública este tipo de hipótesis (sin que la misma sea realmente comprobada), no solo se distorsiona gravemente la comprensión del fenómeno, sino que, además, se emite un mensaje sumamente negativo en dos direcciones: hacia la población, de pánico y alarma pública, y hacia los agentes del Sistema Penal, líneas para la imposición de políticas de mano dura, de restricción de derechos y libertades, lo que abre las puertas a la arbitrariedad. Lo primero busca legitimar a lo segundo. Las empresas de comunicación y algunos sectores opositores, en algunos casos por torpeza políti$\mathrm{ca}$, en otros porque creen en el autoritarismo policial y penal, le hacen el juego y promueven estas lógicas.

\section{Referencias}

Antillano, A. (2007). Estudios sobre la policía en Venezuela. En L. Gabaldón \& A. Antillano, La policía venezolana: desarrollo institucional y pers- 
pectivas de reforma al inicio del tercer milenio (pp. 17-63) Tomo 1. Caracas: CONAREPOL.

Antillano, A. (2010). ¿Qué conocemos de la violencia policial en Venezuela? Las investigaciones e hipótesis sobre el uso de la fuerza física por la policía. Espacio Abierto, 19(2), 331-345.

Antillano, A. (2012). Seguridad y política en la Venezuela bolivariana: La seguridad en el debate político venezolano entre 1998-2009. Espacio Abierto, 21(4),701-726.

Antillano, A. (2014). La reforma policial en la Venezuela bolivariana. En J. Zavaleta, El laberinto de la inseguridad ciudadana: bandas criminales, seguridad de fronteras y regimenes penitenciarios en América Latina (pp. 63-92). Buenos Aires: CLACSO.

Antillano, A. \& Centro para la Paz y los Derechos Humanos de la UCV. (2007). Características de la policía venezolana. En L. Gabaldón \& A. Antillano, La policía venezolana. Desarrollo institucional y perspectivas de reforma al inicio del tercer milenio (pp. 65-158). Venezuela: CONAREPOL.

Ávila, K. (2010). La instrumentalización del delito: política, empresas de comunicación e inseguridad. Sobre cómo la inseguridad logró posicionarse en el primer lugar de la agenda pública en Venezuela. Espacio Abierto, 19(2), 297-329. Recuperado de http://www.produccioncientifica.luz.edu.ve/index.php/espacio/article/view/1397/1399

Ávila, K. (2013). Campañas securitarias: el órgano de investigaciones criminalísticas. Espacio Abierto, 22(3),701-730. Recuperado de http://www. redalyc.org/articulo.oa?id=12229041010

Bandeira, A. (2011). Los controles a los tráficos de armas y municiones. En APORTES, Seguridad Regional como Politica Común (pp. 2-9). San José: Friedrich-Ebert-Stiftung.

Bandeira, A. \& Bourgois, J. (2006). Armas de fuego: ¿protección? ¿O riesgo? Guía Práctica. Suecia: Foro Parlamentario sobre Armas Pequeñas y Ligeras. Baratta, A. (1998). Criminología Crítica y Crítica del Derecho Penal (5. Ed.). México: Siglo XXI editores.

Batton, C., \& Wilson, S. (2006). Police Murders: An Examination of Historical Trends in the Killing of Law Enforcement Officers in the United States, 1947 to 1998. Homicide Studies, 10(2), 79-97.

Becker, H. (1971). Los Extraños. Sociología de la Desviación. Buenos Aires: Editorial Tiempo Contemporáneo. 
Bernal, F. (2015, marzo 11) 57 funcionarios fueron destituidos por extorsióny secuestro. Recuperado de http: / globovision.com/bernal-57-funcionarios-fueron-destituidos-por-extorsion-y-secuestro/ Bernal, F. (2015, abril 30) Bernal sale de la comisión de reforma policial, asume el ministro González. Recuperado de http://www.panorama.com.ve/sucesos/Bernalsale-de-la-comision-de-reforma-policial-asume-el-ministro-Gonzalez-20150430-0060.html

Birkbeck, C. (2001). El 'empresario moral' venezolano: crítica social e identidad durante la segunda mitad del siglo XX. Espacio Abierto, 10(3), 373-405.

Briceño, R. (2009). Venezuela en un mundo de violencia globalizada. En R. Briceño, O. Ávila \& A. Camardiel, Inseguridady violencia en Venezuela. Informe 2008 (pp. 15-43). Caracas: LACSO.

Briceño, R. (2012). La comprensión de los Homicidios en América Latina: ¿Pobreza o Institucionalidad? Revista Ciência \& Saúde Coletiva, 17(12), 3159-3170.

Briceño, R., Camardiel, A., Ávila, O., De Armas, E., \& Zubillaga, V. (1997). La cultura emergente de la violencia en Caracas. Revista venezolana de Economia y Ciencias Sociales, 3(2-3), 195-214.

BBC Mundo. (2014, noviembre 12). Los 5 países con más y con menos homicidios en América Latina [Archivo de video]. Recuperado de http://www. bbc.co.uk/mundo/noticias/2014/12/141211_america_latina_homicidios_oms_ac

Chirinos, A. (2013, diciembre 27). Mataron a cuatro guardias en emboscada al salir de fiesta en El Junquito. El Nacional. Recuperado de http:/ /www. el-nacional.com/sucesos/Mataron-guardias-emboscada-fiesta-Junquito_0_325767601.html

Cohen, L., Klugegel, J., \& Land, K. (1981). Social inequality and predatory criminal victimization: An exposition and test of a formal theory. American Sociological Review, 46, 505-524.

Datanalisis. (2014). Encuesta Nacional Ómnibus. Recuperado de http:// es.scribd.com/doc/243596912/Omnibus-Septiembre-2014-pdf

Del Olmo, R. (1990) Segunda Ruptura Criminológica. Caracas: CDCH, ICP, Facultad de Ciencias Jurídicas y Políticas, UCV.

Durkheim, E. (1893). La división del trabajo social. España: Akal.

Durkheim, E. (1895). Las reglas del método sociológico. Barcelona: Ediciones Folio S.A. 
El Parraquiano. (2015, abril 14). Asesinato de funcionarios de PoliSucre en Los Dos Caminos. Recuperado de https://www.youtube.com/ watch? $\mathrm{v}=\mathrm{X}$ TnDQRR041g

El Universal. (2015, abril 21). 57\% de los policías asesinados cayeron por robo del arma. Recuperado de http:/ / www.eluniversal.com/sucesos/150421/57de-los-policias-asesinados-cayeron-por-robo-del-arma

Fernández, J., \& Tabares, E. (2013). Homicidios en Venezuela (CICPC). En Sentido e impacto del uso de armas de fuego en Venequela. Caracas: Comisión Presidencial para el Control de Armas y Desarme y Universidad Nacional Experimental de la Seguridad.

Fondevilla, G., \& Meneses, R. (2014). The Problems and Promises of Research on Deaths Due to Legal Intervention in Latin America. Homicide Studies, 1-14. doi: 10.1177/1088767914550714

Fridell, L., \& Pate, A. (1997). Death on patrol: killings of American law enforcement officers. En R. Dunham, \& G. Alpert, Critical Issues in Policing (pp. 580-608). New Orleans: Prospect Heights, Waveland Press. Fundación para el Debido Proceso (FUNDEPRO). (2015, mayo 3). Mil 205 efectivos policiales han sido asesinados en cinco años. Recuperado de http:/ / www.eluniversal.com/sucesos/150603/mil-205-efectivos-policialeshan-sido-asesinados-en-cinco-anos; 138 funcionarios de seguridad ultimados en elpais en 5 meses. Recuperado de http:/ / www.el-nacional.com/sucesos/funcionarios-seguridad-ultimados-pais-meses_0_639536222.html

Gabaldón, L. (1993). Policía, incertidumbre y violencia en América Latina: una alternativa al modelo del Estado autoritario. En Derecho Penal y Criminología, XV (pp. 193-210). Bogotá: Universidad Externado de Colombia.

Gabaldón. L. (2013). Exposición y riesgo en la seguridad física de los funcionarios policiales. Propuesta preliminar para proyecto de investigación acción. Caracas: Mimeo.

Gabaldón, L., \& Birkbeck, C. (2003). Policía y fuerza física en perspectiva intercultural. Caracas: Nueva Sociedad.

Garfinkel, H. (1956). Conditions of successful degradation ceremonies. American Journal of Sociology, 61, 420-424.

Globovisión (2015, junio 4) Claves ¿Quién es Julio "Julito” Vélez. Recuperado de http:/ /globovision.com/claves-quien-es-julio-julito-velez/

González López, G. (2015, abril 24) Ministro González López aseguró que asesinatos de policias presuntamente tendrian fines políticos. Recu- 
perado de http://www.noticierovenevision.net/politica/2015/ abril/20/123925=ministro-gonzalez-lopez-aseguro-que-asesinatos-de-policias-presuntamente-tendrian-fines-politicos; Tweets de la cuenta del Ministro de Interior (@GonzalezMPPRIJP) de fechas 2015, junio 19 (https://twitter.com/GonzalezMPPRIJP/ status/589801196656975872) ; (https://twitter.com/GonzalezMPPRIJP/status/589802976195305472) y junio 21 (https://twitter.com/ GonzalezMPPRIJP/status/590527474896863232).

Iglesias, M. (2010, julio 15) Índice de policías muertos a tiros aumenta a 52\% en Caracas. Recuperado de http://www.eluniversal.com/2010/07/15/ sucgc_art_indice-de-policias-m_1972992

INE. (2010). Encuesta Nacional de Victimizacióny Percepción de Seguridad Ciudadana. Caracas: Consejo Nacional de Prevención y Seguridad Ciudadana.

IVAD. (2015). Gestión de gobierno y coyuntura política. Estudio Nacional. Del 08 al 16 de agosto de 2015. Venezuela. Recuperado de http://doctorpolitico. com/wp-content/uploads/2015/08/IVAD-Agosto-2015.pdf

Izquiel, L. (2015) 2014, récord de violencia criminal. Recuperado de http:// www.lapatilla.com/site/2015/01/04/luis-izquiel-2014-record-deviolencia-criminal/

Kaminski, R., Jefferis, E., \& Gu, J. (2003). Community Correlates of Serious Asssaults on Police. Police Quarterly, 6(2), 119-149, doi: 10.1177/1098611103006002001

Kaminski, R., \& Marvell, T. (2002). A comparison of changes in police and general homicides: 1930-1998. Criminology, 40, 119-149.

Kaminski, R., \& Martin, J. (2000). An analysis of police satisfaction with defense and control tactics. Policing an International Journal of Police Strategies \& Management, 23(2), 132-153.

Kraus, J. (1987). Homicide While at Work: Persons, Industries, and Occupations at High Risk. American Journal of Public Health, 1285-1289.

Márquez, P., \& Castillo, A. (2002). ¿Nuevas soluciones a viejos problemas?: las policías municipales del Área Metropolitana de Caracas. En R. Briceño León, \& R. Pérez (Comps.), Morir en Caracas (pp. 147-178). Caracas: UCV.

Matthews, R. (2014). Realismo crítico: un análisis estructural. Política Criminal, Revista Electrónica Semestral de Políticas Públicas en Materias Penales, 9, 182-212. 


\section{I Keymer Ávila}

Merton, R. (1938). Social structure and anomie. American Sociological Review, 3, 672-682.

Ministerio del Poder Popular para la Salud (MPPS). (2010-2012) Anuarios de Mortalidad. Venezuela. Recuperado de http://www.mpps.gob.ve/ index.php?option $=$ com_phocadownload $\& v i e w=$ category $\& i d=11: a$ nuarios-de-mortalidad\&Itemid $=915$

Ministerio Público (2005-2007) Informes Anuales. Venezuela. Recuperado de http://www.ministeriopublico.gob.ve/c/document_library/get_ file?p_1_id=34801\&folderId=34420\&name=DLFE-928.pdf ;http: / / www.mp.gob.ve/c/document_library/get_file?p_l_id=29946\&folde $\mathrm{rId}=34536 \&$ name=DLFE-940.pdf ; http:/ / www.ministeriopublico. gob.ve/c/document_library/get_file?p_1_id=34823\&folderId=3442 2\&name $=$ DLFE-957.pdf

Ministerio Público. (2016). Informe Anual de Gestión 2015. Venezuela.

Monsalve, Y. (2006). Repercusiones del sistema de justicia en el castigo policial. Capitulo Criminológico, 34-1.

Monsalve, Y., \& Gabaldón, L. (2012). Seguridad ciudadana, planificación y discurso político en Venezuela. Espacio Abierto, 21, 502-518.

Noelle-Neumann, E. (1995). La espiral del silencio. Opinión Pública: nuestra piel social. Barcelona: Paidós Comunicación.

Núñez, G. (2006). Orígenes y desarrollo del aparato policial venezolano. Politeia, 29(37), 123-146.

PNB (2015, marzo 23). PNB despliega más de 14 mil funcionarios en Semana Santa 2015. Recuperado de http://cpnb.gob.ve/index.php/noticias/internas/1026-pnb-despliega-mas-de-14-mil-funcionarios-ensemana-santa-2015

Programa Naciones Unidas para el Desarrollo (PNUD). (2013). Informe Regional de Desarrollo Humano (IDH) 2013-2014. Nueva York: PNUD. PROVEA. (1989-2014). Informes Anuales. Caracas.

Oficina de las Naciones Unidas Contra La Droga y el Delito (ONUDD). (2013). Homicide Statistics 2013. Viena: ONUDD.

Ramírez, D. (2013, diciembre 30) Robacarros matan a funcionaria del Cicpc frente a supadre. Recuperado de http:/ / www.eluniversal.com/sucesos/131230/ robacarros-matan-a-funcionaria-del-cicpc-frente-a-su-padre

Real Academia Española. (2001). Diccionario de la Lengua Española. Vigésima segunda edición. Tomo I. Madrid. 
República Bolivariana de Venezuela, Presidencia de la República. Decreto $\mathrm{N}^{\circ} 7.453$, mediante el cual la Dirección Nacional de los Servicios de Inteligencia y Prevención (DISIP), una vez publicado el presente Decreto, será el Servicio Bolivariano de Inteligencia Nacional (SEBIN) (1 de junio de 2010).

República Bolivariana de Venezuela. (2000). Constitución de la República Bolivariana de Venezuela.

República Bolivariana de Venezuela, Asamblea Nacional. Ley Especial del Régimen Municipal a dos niveles del AMC (1 de octubre de 2009). República Bolivariana de Venezuela. Ley Orgánica del Servicio de Policía y del Cuerpo de Policía Nacional Bolivariana (7 de diciembre de 2009).

Rísquez, R. (2015, abril 20) Policías piden reunión con Freddy Bernaly penas más severas para homicidas de funcionarios. Recuperado de http://runrun.es/ nacional/venezuela-2/198313/policias-piden-reunion-con-freddybernal-y-penas-mas-severas-para-homicidas-de-funcionarios.html Romero, J. (2015). Evaluación del Nuevo Modelo Policial Venezolano: carácter civil, derechos bumanos y participación cindadana (Trabajo de Grado Académico de Magíster en Ciencia Política. Universidad Simón Bolívar, Caracas, Venezuela).

Sanjuán, A. (1997). La criminalidad en Caracas. Revista Venezolana de Economía y Ciencias Sociales. 3(2-3), 215-254.

Sanjuán, A. (2003). "Dinámicas de la violencia en Venezuela: tensiones y desafíos para la consolidación de la democracia”. En L. Bobea, Entre el crimen y el castigo. Seguridad ciudadana y control democrático en América Latina y el Caribe (pp. 119-126). Venezuela: Nueva Sociedad, FLACSO y Woodrow Wilson International Center for Scholars.

Sanjuán, A. (2008). La revolución bolivariana en riesgo, la democratización social en cuestión. La violencia social y la criminalidad en Venezuela entre 1998-2008. Revista Venezolana de Economía y Ciencias Sociales, 14(3), 145-174.

Sanjuán, A. (2012). Seguridad ciudadana en Venezuela. Washington: Woodrow Wilson International Center for Scholars. Recuperado de http:// wilsoncenter.org/event/citizen-security-venezuela

Sanjuán, A. (2013). La crítica situación de seguridad ciudadana en Venezuela: características, causalidades, políticas y desafíos. En C. Basombrio (Ed.), ¿A dónde vamos? Análisis de políticas públicas de seguridad ciudadana en América Latina (pp. 297-347). Washington, Wilson Center. 


\section{4 / KeYMer ÁviLA}

Shaw, C., \& McKay, H. (1969). Juvenile delinquency and urban areas. Chicago: Univesity of Chicago Press.

Telesur (2014, octubre 15). Paramilitar colombiano dirigió asesinato de diputado venezolano. Recuperado de http://www.telesurtv.net/news/ Paramilitar-colombiano-dirigio-asesinato-de-diputado-venezolano-20141015-0076.html

Zaffaroni, E. (1993). Muertes Anunciadas. Bogotá: Temis.

\section{Páginas web}

http:/ /www.eluniversal.com/

http://globovision.com

http://www.ine.gov.ve/

http://www.noticierovenevision.net/

http://runrun.es/

http://www.telesurtv.net

http://www.ultimasnoticias.com.ve/ 